\title{
A Solution To The Dilemma BetWeEn R\&D EXPANSION AND THE PRODUCTIVITY DECLINE: LESSONS From THE R\&D MODELS IN AMAZON AND FINLAND
}

\author{
Yuji Tou ${ }^{1}$, Chihiro Watanabe ${ }^{2,3}$, Kuniko Moriya ${ }^{4,2}$, Pekka Neittaanmäki ${ }^{2}$ \\ ${ }^{1}$ Dept. of Ind. Engineering \& Magm., Tokyo Institute of Technology, Tokyo, Japan \\ ${ }^{2}$ Faculty of Information Technology, University of Jyväskylä, Finland \\ ${ }^{3}$ International Institute for Applied Systems Analysis (IIASA), Austria \\ ${ }^{4}$ Research and Statistics Department, Bank of Japan, Tokyo, Japan
}

\begin{abstract}
As a consequence of the two-faced nature of information and communication technology (ICT), a majority of ICT leaders have been confronting the critical problem of a dilemma between R\&D expansion and productivity decline in the digital economy. However, Amazon has been able to accomplish a skyrocketing increase in $R \& D$ and market capitalization. Finland has also accomplished balanced advancement not only of welfare but also economic resurgence. This paper attempted to elucidate the miracle of two ICT leaders. By means of a comparative empirical analysis of respective development trajectories, the sources of their success were analyzed thereby the comparative advantage and disadvantage of each respective trajectories supportive to find a practical solution to the critical problem of a dilemma were identified. The sources of both successes can be attributed to harnessing the vigor of soft innovation resources from the marketplace. However, contrary to Amazon's complementary use, Finland has depended on substitutionary use. While this approach contributes to easy resurgence, it casts a shadow to the innovative growth in the future. An insightful suggestion regarding balanced sustainable growth by cross learning was thus provided.
\end{abstract}

\section{KEYWORDS}

Digital economy, soft innovation resources, Amazon, Finland, dilemma between $R \& D$ and productivity

\section{INTRODUCTION}

Notwithstanding the critical problem of a dilemma between $R \& D$ expansion and productivity decline that a majority of information and communication technology (ICT) leaders have been confronting in the digital economy [1], [2], Amazon has been able to accomplish a skyrocketing increase in $\mathrm{R} \& \mathrm{D}$ and market capitalization.

Fig. 1 illustrates the world's top 25 R\&D leaders by their R\&D expenditure in 2017, which demonstrates a notable R\&D growth in software and Internet leaders. Noteworthy is Amazon's conspicuous jump. It invested US\$ 22.6 billion R\&D in 2017 and jumped up to the ranks of the world's top R\&D firm, surpassing rival global ICT leaders.

In corresponding to such a rapid and notable increase in $R \& D$ investment, Amazon has accomplished a skyrocketing increase in its market capitalization (MC). It hit the US\$ 1 trillion MC level in 2018. Consequently, Amazon was close to being the world's biggest Internet 
International Journal of Managing Information Technology (IJMIT) Vol.11, No.2, May 2019

company in 2018, competing with Apple, as demon-strated in Fig. 2. It briefly exceeded the level of Apple in December 2018 and also in January 2019, as demonstrated in Fig. 2-2.

This R\&D-driven accomplishment may provide a constructive suggestion to the solution to the dilemma between R\&D expansion and productive decline [8]. Finland, one of the world ICT leader, has also accomplished a balanced advancement not only of welfare but also economic growth by means of a notable resurgence [9].

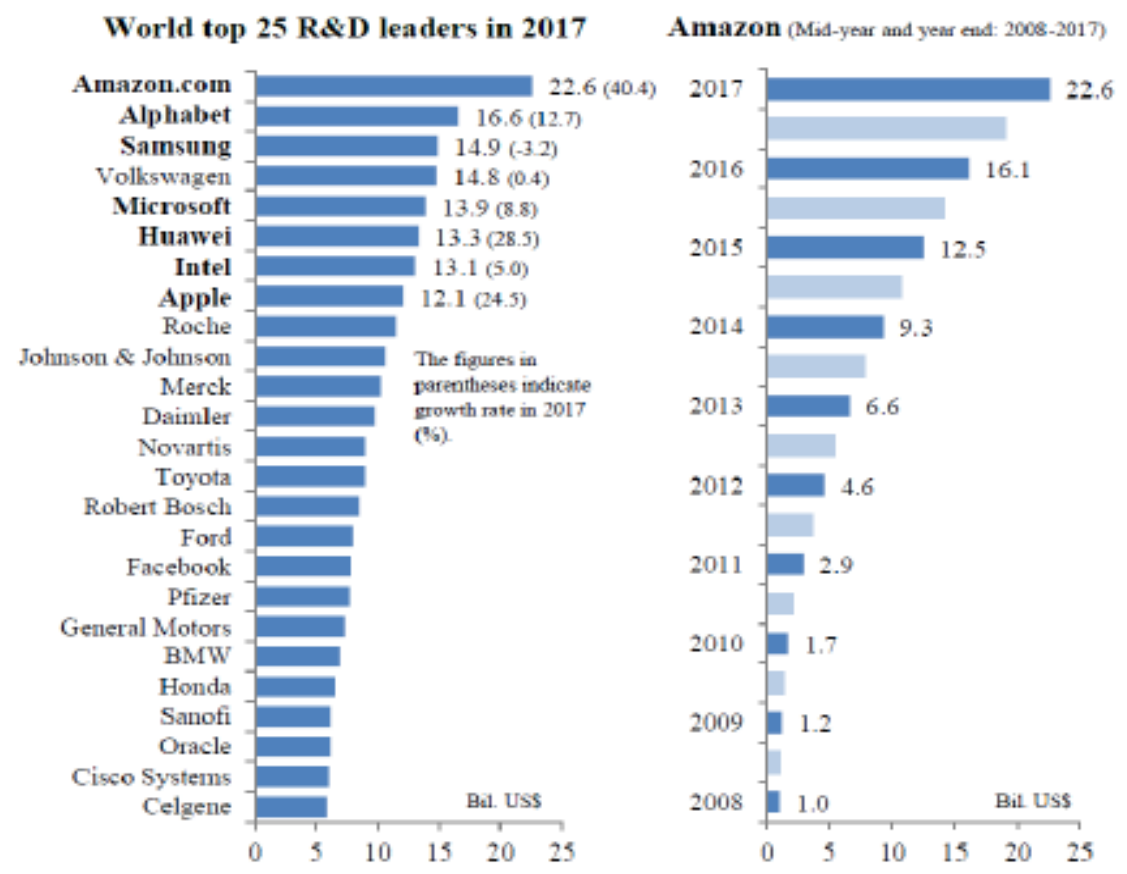

Figure 1. Amazon's conspicuous jump into the position of world's R\&D leader in 2017.

Original sources: [3], [4].

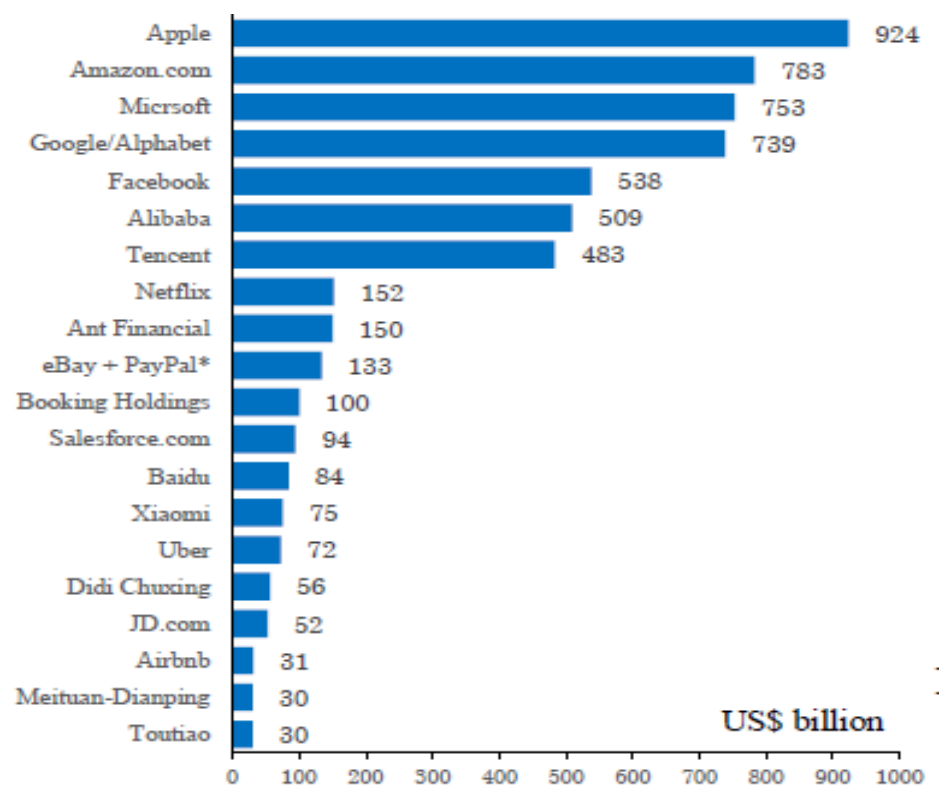

Figure 2. Market capitalization of the top Internet companies worldwide (as of May 2018). Original source: [5]. 


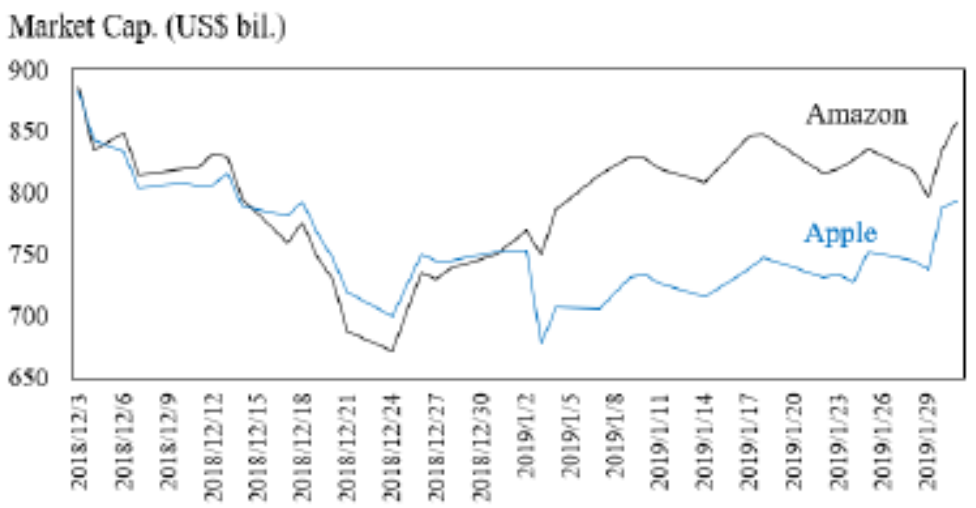

Figure 2-2. Trends in MC of Amazon and Apple (03 Dec. 2018 - 31 Jan. 2019).

Original source: [6], [7].

Fig. 3 compares GDP growth rate in 11 leading countries by taking averages of 2010-2012, 20132015 and 2016-2018. While Finland suffered the lowest GDP growth in the first two periods examined, it demonstrated a notable resurgence from 2016 [9]. It accomplished the highest GDP growth after Singapore in 2016-2018. Contrary to Singapore's growth oriented development with lower happiness/welfare level, Finland accomplished also the highest level of happiness/welfare as demonstrated in Fig. 4. Thus, Finland succeeded to achieve a balanced development (see the details of the statistics in Table A1 in the Appendix).

Inspired by these successes, this paper attempted to extract constructive suggestions supportive to finding a practical solution to the critical problem of a dilemma between R\&D expansion and productivity decline in the digital economy.

To date, a significant number of studies attempted to analyze their notable performances and unique business models (e.g., [9, 12-17]).

However, none has analyzed their R\&D models from the view point of providing a solution to the above dilemma.

This paper attempted a comparative empirical analysis of the R\&D-driven development trajectories between two ICT leaders and identified the comparative advantage and disadvantage of each respective trajectories of two ICT leaders.

An insightful suggestion by their cross learning was thus provided. Organization of this paper is as follows: Section 2 over reviews dilemma between R\&D increase and productivity decline. Solution to this critical problem is discussed in Section 3. Section 4 examined lessons from Amazon and Finland. Section 5 summarizes the noteworthy findings, policy suggestions, and future research. 


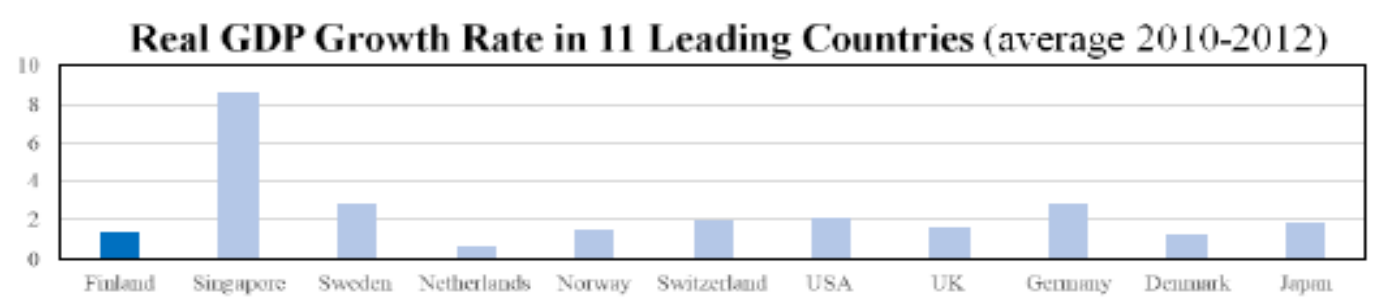

Real GDP Growth Rate in 11 Leading Countries (average 2013-2015)

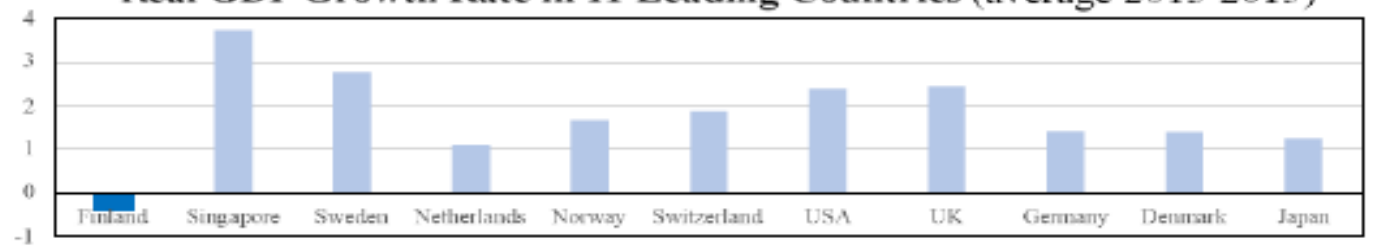

Real GDP Growth Rate in 11 Leading Countries (average 2016-2018)

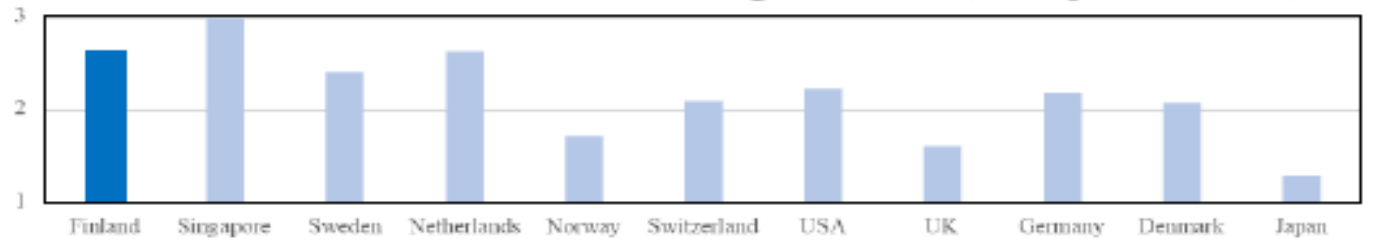

Figure 3. Finland notable resurgence in GDP growth among 11 countries. Source: [10].

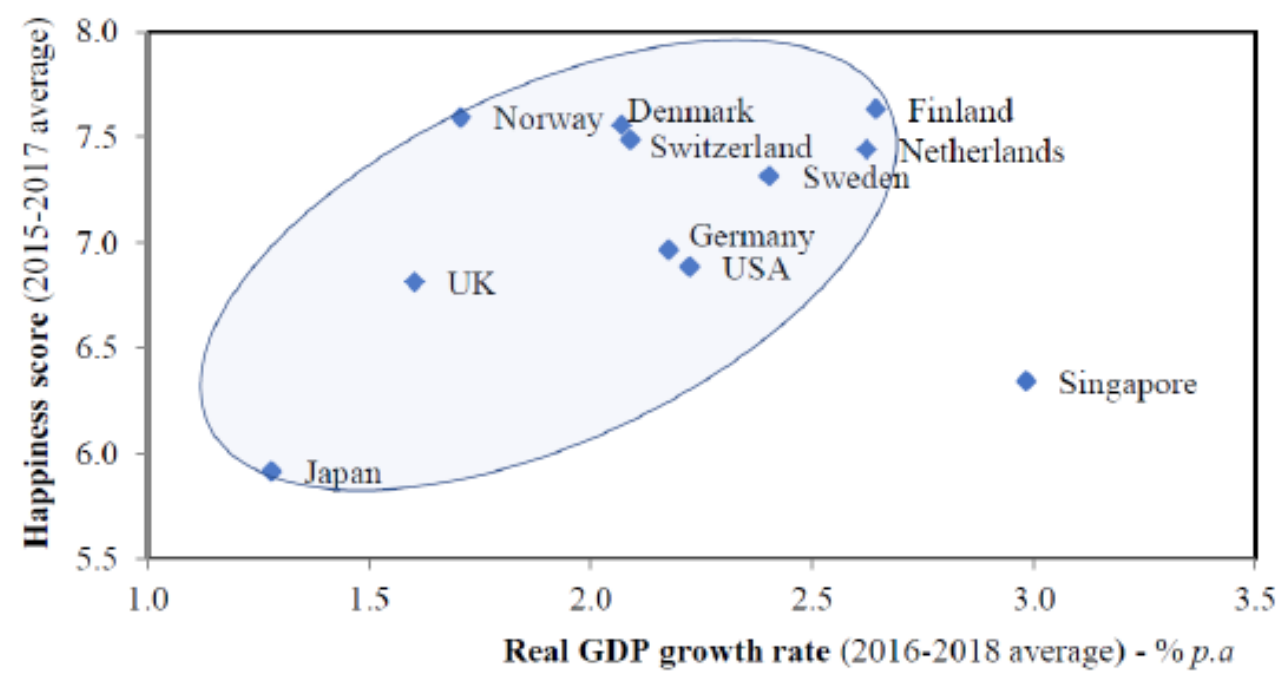

Figure 4. Comparison of balanced development of economic growth and happiness in 11 leading countries. Sources: [10], [11].

\section{Dilemma Between R\&D Expansion And Productivity Decline}

\subsection{BIPOLARIZATION OF ICT-DRIVEN DEVELOPMENT TRAJECTORY}

ICT in which network externalities function to alter the correlation between innovations and institutional systems which creates new features of the innovation leading to exponential increase [18]. Schelling [19] portrayed an array of logistically developing and diffusing social mechanisms 
stimulated by these interactions. Advancement of the Internet further stimulates these interactions and accelerates ICT's logistically developing and diffusing feature.

Given the logistic development and diffusion, ICT-driven growth follows a sigmoid trajectory which continues to grow until it reaches carrying capacity (upper limit of growth). In this trajectory, while growth rate continues to increase before reaching to inflection point corresponding to the half level of carrying capacity, it changes to decrease after exceeding the inflection point. Thus, ICT-driven logistic growth incorporates bi-polarization fatality, increase and decrease of marginal productivity between before and after the inflection point.

Fig. 5 demonstrates development trajectories in 140 countries and 500 global ICT firms in 2016 taking ICT advancement and its marginal productivity to GDP per capita and sales, respectively. Fig. 5 demonstrates clear bi-polarization between ICT-growing economies and ICT-advanced economies. While the former enjoys a virtuous cycle between ICT advancement and productivity increase, the latter suffers a vicious cycle as further ICT advancement results in productivity decline.
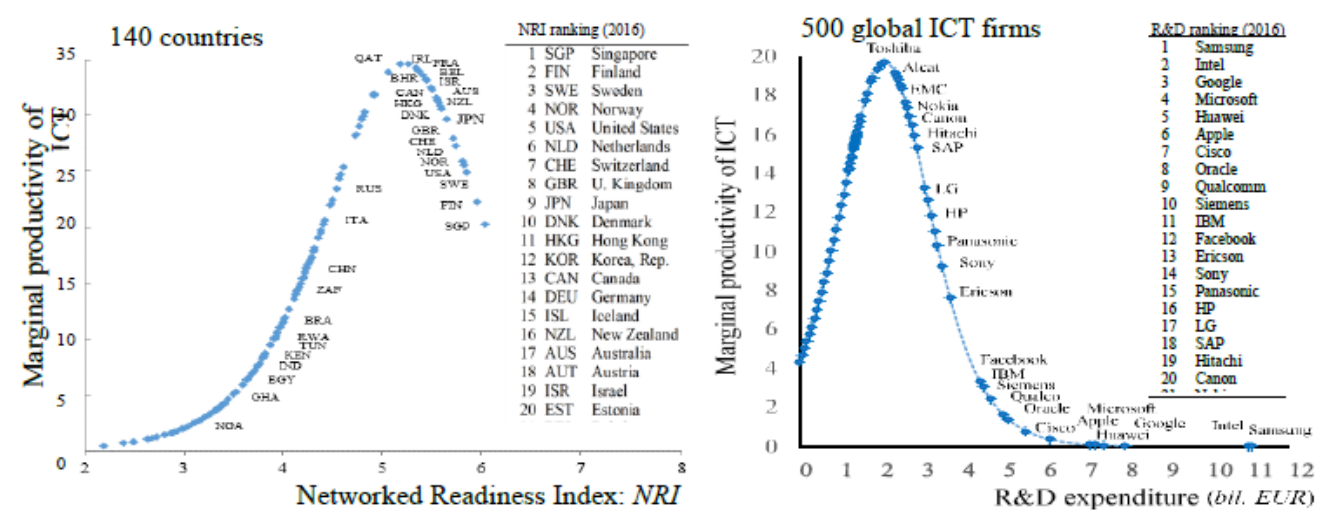

Figure 5. Bipolarization of ICT-driven development trajectories in 140 countries and 500 global ICT firms (2016).

* Amazon is included in the declining group as its market capitalization is conspicuous while $R \& D$ investment is counted smaller in the following sources as Amazon describes R\&D as technology and content in its annual report. Sources: [20-22].

This bipolarization, fatal to ICT-driven development, causes the critical problem of a dilemma between R\&D expansion and a productivity decline that a majority of ICT leaders have been confronting in the digital economy. In order to attain the growth target that is essential for the survival of global ICT firms, highly R\&D intensive firms (HRIFs), which exceeded the inflection point, attempt R\&D expansion. However, contrary to anticipation, this effort causes productivity decline resulting in growth decrease.

\subsection{DILEMMA DERIVED FROM R\&D EXPANSION}

Digital value V created in an IoT society can be depicted as follows [23], [24]:

$$
V=F(X, T)=F(X(T), T) \approx F(T) \text { Growth rate: } \frac{\Delta V}{V}=\left(\frac{\partial V}{\partial T} \cdot \frac{T}{V}\right) \cdot \frac{\Delta T}{T} \approx \frac{\partial V}{\partial T} \cdot \frac{R}{V} .
$$

where T: gross ICT stock; $\mathrm{X}$ : other production factors; and R: R\&D investment $(\Delta T \approx R)$. 
International Journal of Managing Information Technology (IJMIT) Vol.11, No.2, May 2019

In long run, since $T \approx \frac{R}{\rho+g}$ gross rate can be: $\frac{\Delta V}{V}=\frac{\partial V}{\partial T} \cdot \frac{R}{V}=\frac{\partial V}{\partial R} \cdot \frac{\partial R}{\partial T} \cdot \frac{R}{V}=(\rho+g) \frac{\partial V}{\partial R} \cdot \frac{R}{V}$

where $\rho$ : rate of obsolescence of technology, g: R\&D growth rate at the initial period.

Given the logistic growth nature of ICT, R\&D-driven development trajectory $\mathrm{Vs}(\mathrm{R})$ can be depicted by the following epidemic function that leads simple logistic growth function (SLG):

$$
\frac{d V}{d R} \approx \frac{\partial V}{\partial R}=a V\left(1-\frac{V}{N}\right), \quad V_{s}(R)=\frac{N}{1+b e^{-a R}}
$$

Table 1 demonstrates this trajectory in 500 global ICT firms in 2016.

Table 1. Development trajectory of 500 global ICT firms (2016).

\begin{tabular}{crrcc}
\hline & $N$ & $a$ & $b$ & adj. $R^{2}$ \\
\hline \multirow{2}{*}{$V_{\mathrm{s}}(R)$} & 59.62 & 1.32 & 15.91 & 0.784 \\
& $(17.39)$ & $(10.98)$ & $(21.87)$ & \\
\hline
\end{tabular}

$\mathrm{N}$ : carrying capacity, a and b: coefficients. The figures in parentheses indicate the tstatistics: all are significant at the $1 \%$ level.

This trajectory can be developed as follows:

$$
b e^{-a R} \equiv \frac{1}{x}, V=\frac{N}{1+\frac{1}{x}}, R=\frac{\ln b x}{a}, \frac{R}{V}=\frac{\ln b x(1+x)}{a N \cdot x}, \frac{\partial V}{\partial R}=\frac{a N \cdot x}{(1+x)^{2}}, \frac{\Delta V}{V} \approx(\rho+g) \frac{\partial V}{\partial R} \cdot \frac{R}{V}=(\rho+g) \cdot \frac{\ln b x}{1+x}(3)
$$
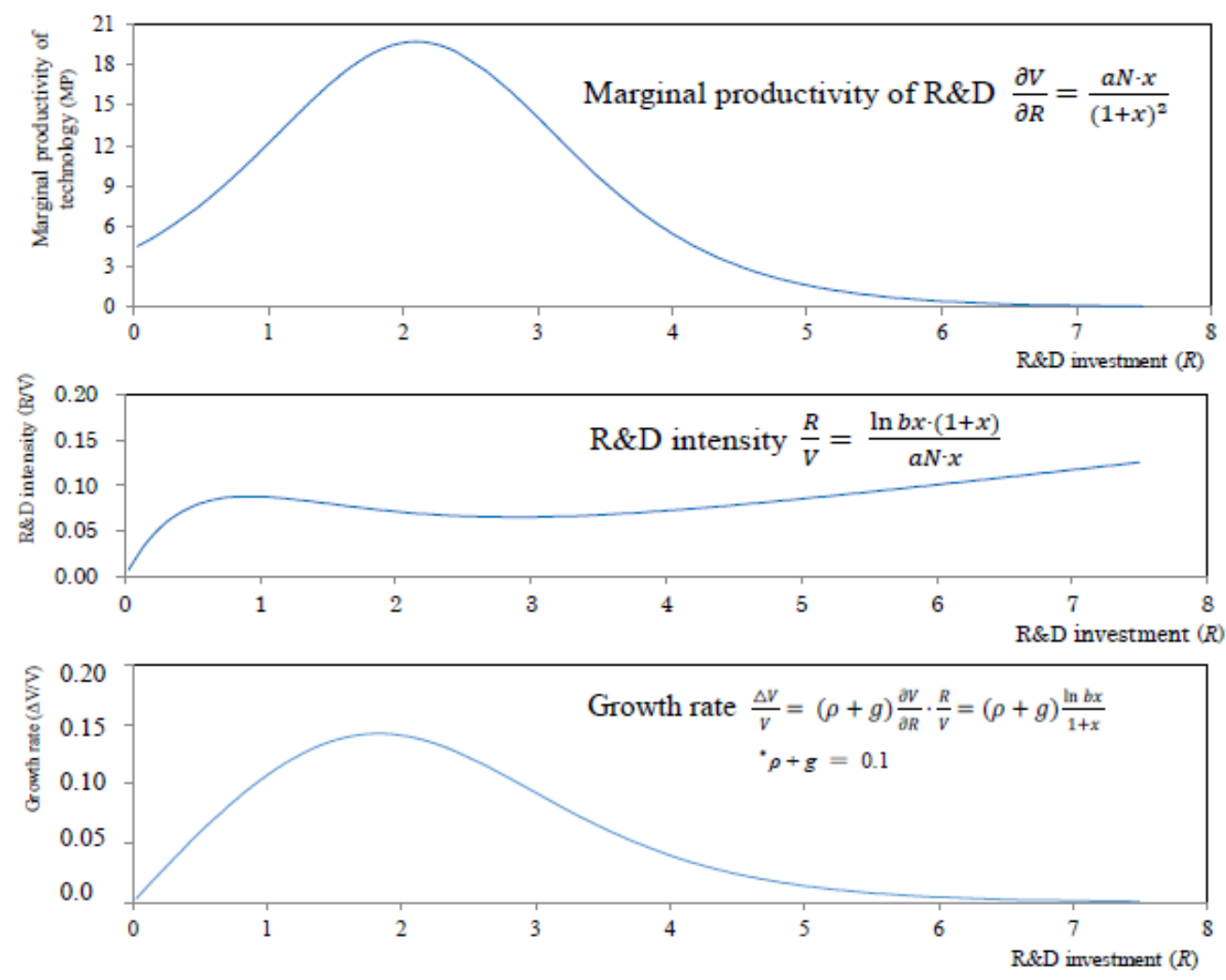

Based on these analyses Fig. 6 examines the consequences of bipolarization in global ICT firms in 2016. 
In order to win the race in the competitiveness race, HRIFs endeavor to sustainable growth by devoting $R \& D$ increase as illustrated in the middle of the Figure. However, it resulted in unsuccessful growth due to a significant productivity decline as demonstrated in the top of the Figure.

Figure. 6. Possible trend in growth rate and contributors to it in global ICT firms in 2016.

This examination suggests that in order to attain the target sustainable growth that is essential for the survival of global ICT firms, HRIFs should find disruptive innovation solutions to overcome this dilemma.

\section{Solution To The Dilemma}

\subsection{COUNTERMEASURE UNDERTAKEN BY HRIFS}

Confronting the aforementioned dilemma, ICT-advanced economies have been endeavoring to find a practical solution by transforming into a new business model.

Given that this dilemma stems from the unique feature of ICT, logistic growth, this feature should be transformed.

As far as the development trajectory depends on the simple logistic growth (SLG) trajectory, its digital value, $\mathrm{Vs}(\mathrm{R})$, saturates with the fixed upper limit which inevitably results in the dilemma as reviewed above. However, once the trajectory shifts to logistic growth within the dynamic carrying capacity (LGDCC), its digital value, VL(R) can continue to increase as it creates new carrying capacity during the process of diffusion trajectory. LGDCC incorporates the selfpropagating function, enhancing the upper limit dynamically as growth proceeds. This function can be depicted as follows:

$$
N_{L}(R)=V_{L}(R)\left(\frac{1}{1-\frac{1}{a} \frac{\Delta V_{L}(R)}{V_{L}(R)}}\right) \quad \Delta V_{L}(R)=\frac{d V_{L}(R)}{d T}
$$

The above analyses demonstrate the new disruptive business model initiated by the global ICT leaders for increasing functionality development by exploring and utilizing external resources that arouse and activate the latent self-propagating function indigenous to ICT as illustrated in Figs. 7 and 8.

Thus, activation of a latent self-propagating function indigenous to ICT though growth as illustrated in Fig. 9 is a key to overcome the dilemma. 
International Journal of Managing Information Technology (IJMIT) Vol.11, No.2, May 2019

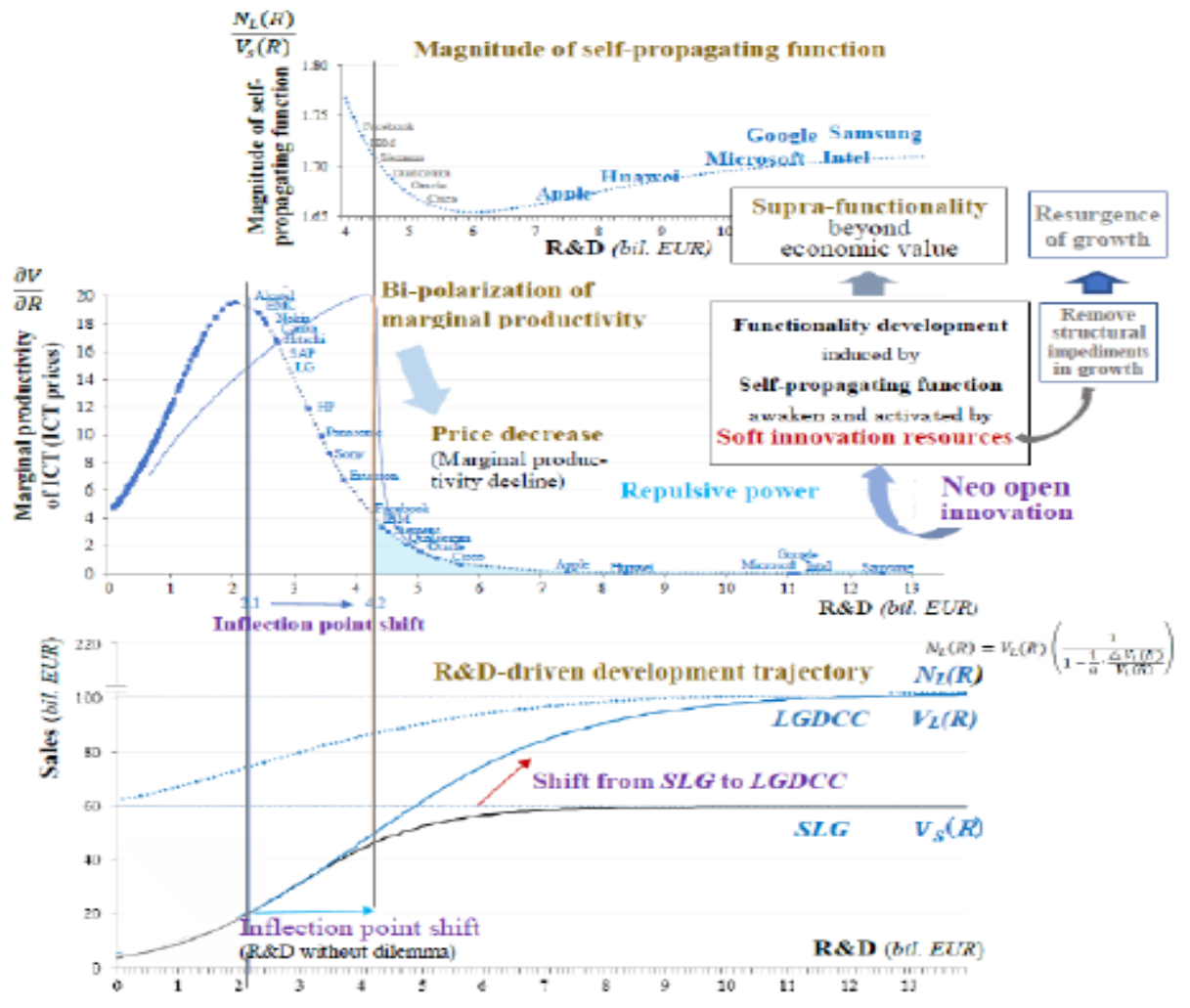

Figure 7. Dynamism in overcoming the dilemma in global ICT firms (2016).

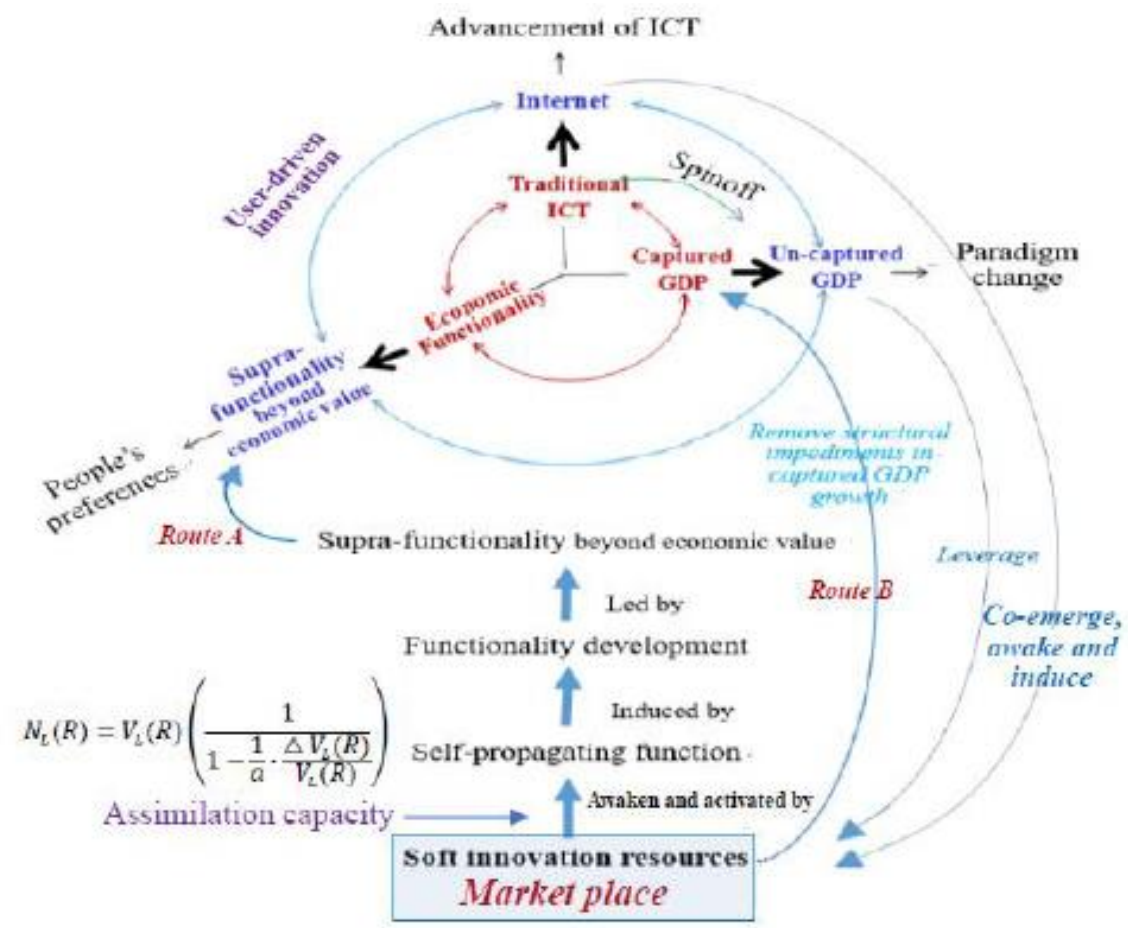

Figure 8 . The disruptive business model initiated by global ICT leaders 


$$
\begin{aligned}
& \begin{array}{l}
\text { Self-propagating } \\
\text { function }
\end{array} \\
& \qquad N_{L}(R)=V_{L}(R)\left(\frac{1}{1-\frac{1}{a} \cdot \frac{\Delta V_{L}(R)}{V_{L}(R)}}\right) \quad \Delta V_{L}(R)=\frac{a V_{L}(R)}{d R} \\
& \frac{\Delta V_{L}(R)}{V_{L}(R)}=\frac{\partial V_{L}(R)}{\partial T} \cdot \frac{T}{V_{L}(R)} \cdot \frac{\Delta T}{T} \approx \frac{\partial V_{L}(R)}{\partial T} \cdot \frac{R}{V_{L}(R)} \propto \frac{\partial V}{\partial R} \cdot \frac{R}{V}
\end{aligned}
$$

Figure 9. Dynamism in activating latent self-propagating function

\subsection{DYNAMiSM in ACTIVATING THE SELF-PROPAGATING FUnCTION}

Fig. 9 demonstrates that explicit growth by means of an increase of a product of marginal productivity of technology and $R \& D$ intensity should be essential to activate self-propagating function indispensable for shifting from a SLG to a LGDCC trajectory that overcomes the dilemma. This is something similar to self-contradiction as a question is to find a solution against marginal productivity decline as a consequence of an R\&D increase.

In order to clarify this contradiction, first, fundamental features of a LGDCC are examined by comparing with those of a SLG.

LGDCC function can be approximated by the following SLG function [25]:

$$
\begin{aligned}
& V_{L}(R)=\frac{N_{k}}{1+b e^{-a R}+\frac{b_{k}}{1-a_{k} / a} e^{-a_{k} R}} \approx \frac{N_{k}}{1+b^{\prime} e^{-a^{\prime} R}} \quad a^{\prime}=a\left(1-\frac{b_{k}}{b}\right)<a, b^{\prime}=b\left(1+\frac{b_{k}}{b} \cdot \frac{1}{1 \frac{a_{k}}{a}}\right)>b \\
& b^{\prime e^{-a^{\prime} R}}=\frac{1}{x}, \frac{\partial V_{L}}{\partial R}=a^{\prime N_{k}} \frac{x}{(1+x)^{2}}, \frac{d \frac{\partial V_{L}}{\partial R}}{d x}=\frac{d \frac{\partial V_{L}}{\partial R}}{d R} \cdot \frac{1}{a^{\prime} x}=a^{\prime} N_{k} \cdot \frac{(1-x)}{(1+x)^{2}}, \frac{d \frac{\partial V_{L}}{\partial R}}{d R}=0 \text { when } x=1\left(R=\frac{\ln b^{\prime}}{a^{\prime}}>\frac{\ln b}{a}\right) \\
& \frac{\partial V_{L}(R)}{\partial R} \approx a^{\prime} V_{L}(R)\left(1-\frac{V_{L}(R)}{N_{k}}\right)<a V_{L}(R)\left(1-\frac{V_{L}(R)}{N_{k}}\right) \quad \text { (see the empirical evidences in Table 2). }
\end{aligned}
$$

These analyses suggest that the LGDCC permits higher R\&D level before marginal productivity changes to decline as its inflection point (ln $\mathrm{b}^{\prime} / \mathrm{a}^{\prime}$ ) is higher than that of the SLG, and also contains a possibility that its marginal productivity of technology is lower than that of the SLG.

Table 2 analyzes the development trajectories of 500 global ICT firms in 2016 by comparing the SLG and the LGDCC.

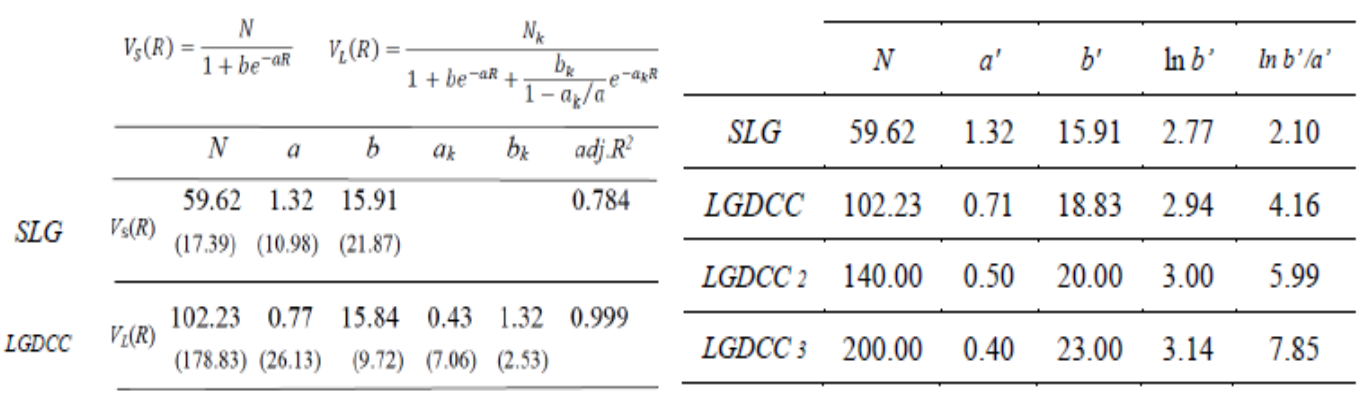

$\mathrm{N}$ and $\mathrm{N}_{\mathrm{k}}$ : carrying capacity, $\mathrm{a}, \mathrm{b}, \mathrm{a}_{\mathrm{k}}$, and $\mathrm{b}_{\mathrm{k}}$ : coefficients 
The figures in parentheses indicate the t-statistics: all are significant at the $1 \%$ level. LGDCC 2 and LGDCC 3 are simulations.

Fig. 10 demonstrates marginal productivity of technology and inflection point of each respective trajectory.

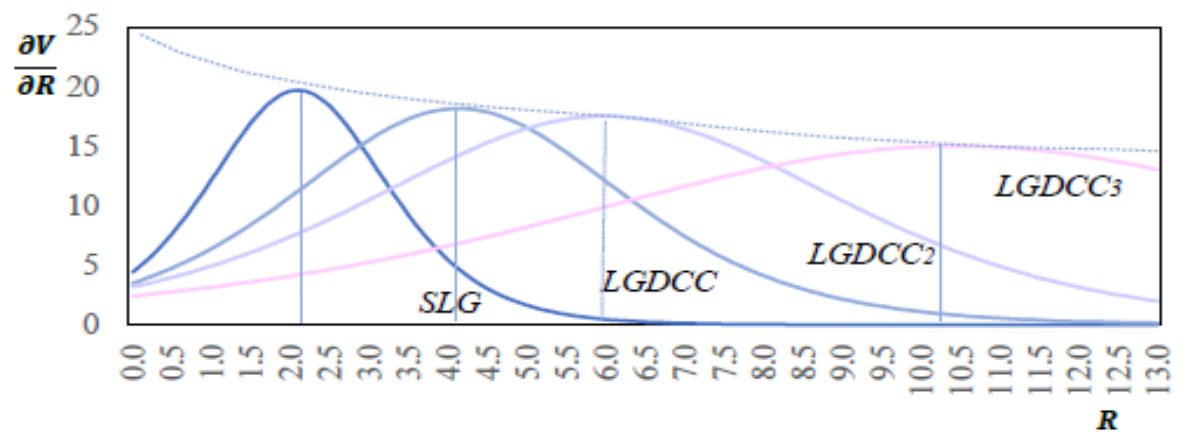

Figure 10. Dynamism enabling higher R\&D without the dilemma

Looking at Fig. 10 we note that while the LGDCC enables higher R\&D before changing to marginal productivity of technology decline, this productivity shifts to lower level as the LGDCC function increases. With these findings, if we look back again Fig. 9, it is evident that R\&D intensity increase plays a key role in activating latent self-propagating function indigenous to ICT and indispensable to shifting to a LGDCC which solves the dilemma.

Considering that while LGDCC enables higher R\&D without productivity decline, it also cannot avoid confronting this decline by depending excessive R\&D. This suggests the significance of harnessing the innovation resources from the external market. The authors in the preceding studies demonstrated the significance of neo open innovation that harness the vigor of soft innovation resources (SIRs) from the market place as illustrated in Fig. 7 [1], [2]. Here, SIRs are considered as a condensate and crystal of the advancement of the Internet (Tou et al., 2018b, $2019 \mathrm{~b}$ ) and consist of the Internet based resources that have been either sleeping or untapped or are results of multisided interaction in the markets where consumer is looking for functionality beyond an economic value. They demonstrated that effective utilization of these resources depends largely on the assimilation capacity that assimilates these resources from the marketplace and assimilate into own business. This capacity depends on a rapid and notable increase in R\&D as Amazon has demonstrated [8]. This scheme is illustrated in Fig. 11.

\section{Assimilation capacity}

$$
z=\frac{1}{1+\frac{\Delta T_{s}}{T_{s}} / \frac{\Delta T_{i}}{T_{i}}} \cdot \frac{T_{i}}{T_{s}}
$$

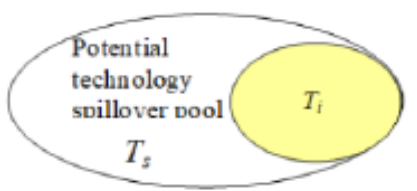

$$
\begin{array}{|ll|}
T_{i} \approx \frac{R_{i}}{\rho+g} \approx \frac{R_{i}}{H} & \begin{array}{l}
R i: \text { R\&D } \\
\rho: \text { rate of obsolescence } \\
\text { of technology } \\
\text { g: R\&D growth rate at initial stage } \\
H: \text { constant }
\end{array} \\
T_{S}=F(I D) & I D: \text { Internet dependence } \\
\hline
\end{array}
$$

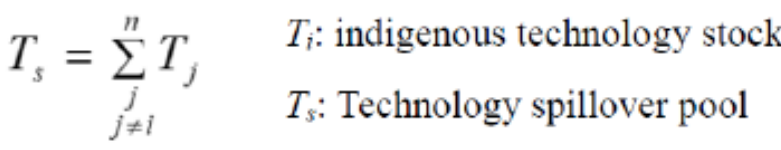

Figure 11. Scheme of measuring dynamic assimilation capacity.

Source: [26]. 
These analyses suggest a dynamism of a core function of the disruptive business model that overcome the dilemma between R\&D expansion and productivity decline as illustrated in Fig. 12.

Core function is to activate latent self-propagating function through growth by means of gross $R \& D$ increase consisting of increases in indigenous $R \& D(R i)$ and assimi- lated external innovation resources centered on SIRs. Increased gross R\&D contributes to growth and activates the latent self-propagating function by enhancing the dynamic carrying capacity of the LGDCC $(\mathrm{NL}(\mathrm{R}))$. This enhancement accele-rates a shift to LGDCC. This shift induces functionality development, leading to supra-functionality beyond economic value.

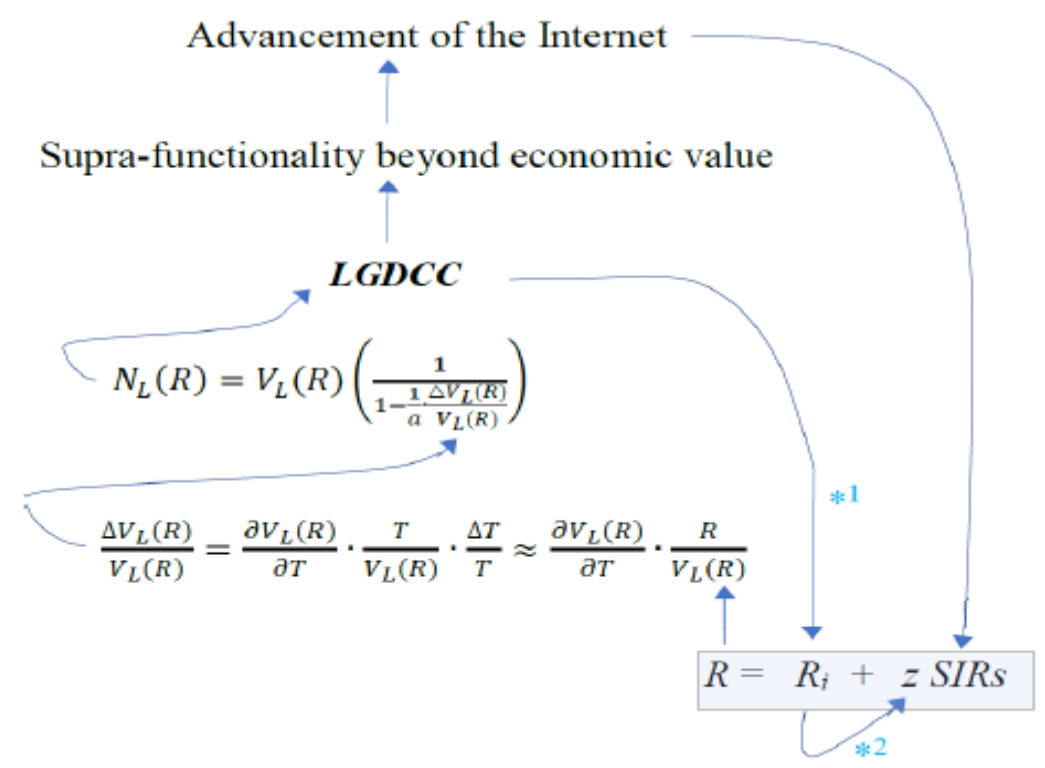

Figure 12. Dynamism of a core function of the disruptive business model.

*1: see Fig. 10; *2: see Fig. 11.

This corresponds to people's preferences shift and induces further advancement of the Internet (this contribution route can be identified as Route A). Furthermore, this advancement accelerates the increasing dependence on uncaptured GDP, which leverages the harnessing of the vigor of SIRs. The Internet promote a free culture, the consumption of which provides utility and happiness to people but cannot be captured through the GDP data, which measure revenue. These identical services are called uncaptured GDP [27], [28]. At the same time, the advancement of the Internet arouses and induces SIRs, as they are a crystal of the Internet. Thus, a virtuous cycle exists between the emergence and utilization of SIRs, supra-functionality beyond economic value, advancement of the Internet, uncaptured GDP dependence, and further leverage to SIRs emergence, as illustrated in Fig. 8.

In addition, it cannot be overlooked that SIRs also contribute to captured GDP increases by removing the structural impediments to its growth (this contribution route can be identified as Route B). An example of this can be observed in Finland's recent resurgence in GDP growth [9].

As a core function of such a comprehensive co-evolutionary system, Fig. 12 suggests that once the engine is fired up, a virtuous cycle for neo open innovation by assimilating SIRs can be expected. Therefore, deployment of such a function as turning on the ignition plays a decisive role in the digital economy. 
International Journal of Managing Information Technology (IJMIT) Vol.11, No.2, May 2019

Based on this understanding, next section explores this function focusing on the effective deployment of gross $R \& D$ resources in the digital economy. Lessons from the successes of $R \& D$ models in Amazon and Finland as reviewed earlier are expected to provide an insightful suggestion to this deployment.

\section{LESSONS From AMAZON AND FinLAND}

\subsection{SimILARITY AND DISPARITY}

As reviewed in the preceding section, the disruptive business model initiated by global ICT leaders can be traced by two contribution routes as summarized in Table 3. Both global ICT leaders, Amazon and Finland have demonstrated conspicuous contributions to respective route [9], [8].

While Amazon has constructed complementary development of both routes, since Finland had deployed the Route A earlier [28], [29], its recent notable resurgence can largely be attributed to the deployment of the Route B [9].

\begin{tabular}{|l|l|l|l|}
\hline & Function & Innovation system & Trigger of innovation \\
\hline Route $A$ & $\begin{array}{l}\text { Generate supra- } \\
\text { functionality beyond } \\
\text { economic vale }\end{array}$ & $\begin{array}{l}\text { Co-evolution between } \\
\text { the Internet, uncaptured } \\
\text { GDP and supra- } \\
\text { functionality beyond } \\
\text { economic value }\end{array}$ & Breakthrough \\
\hline Route $B$ & $\begin{array}{l}\text { Remove structural } \\
\text { impediments in } \\
\text { growth }\end{array}$ & Resurgence & $\begin{array}{l}\text { Change in institutional } \\
\text { systems }\end{array}$ \\
\hline
\end{tabular}

Table 3. Options of growth routes

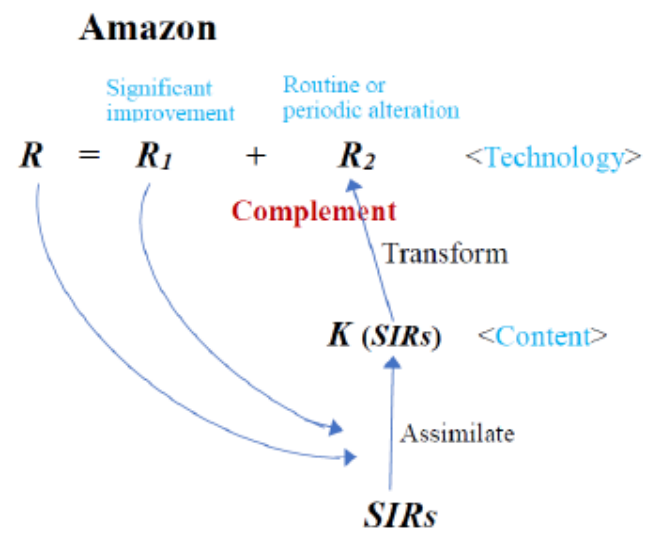

Finland

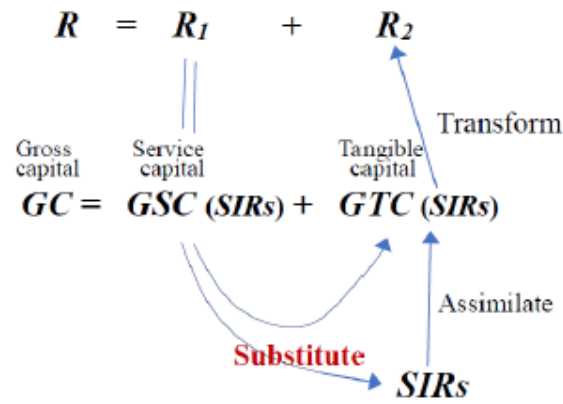

Fig. 13 compares R\&D model of both global ICT leaders.

Amazon has jumped up to the world's top R\&D firm in 2017 by complementing significant improvement endeavors and routine or periodic alterations endeavors based on its unique R\&D model. The latter endeavors have been transformed into the former by absorbing SIRs in the marketplace and assimilating them to its business [8].

Contrary to Amazon's such complementary use, Finland has depended on substitutionary use of SIRs. In Finland SIRs substituted for gross service capital (GSC) centered on R\&D. These SIRs spilled over to gross tangible capital (GTC) and removed structural impediments in growth 
International Journal of Managing Information Technology (IJMIT) Vol.11, No.2, May 2019

thereby contributed to notable resurgence in GDP growth while relieving from the increasing burden of R\&D investment [9]. This functioned transformation of GTC into innovative function similar to R\&D.

The authors in the previous study demonstrated this substitutionary dynamism enabling Finland a notable resurgence [9].

Table 4 demonstrates that Finland has substituted SIRs for GSC centered on R\&D (R) from 2010. Here, given that SIRs are a crystal of the Internet, the Internet dependence (I) was used as a proxy of SIRs (pi and pj are price of the Internet and $R \& D$, respectively).

$$
\begin{aligned}
& \ln \frac{I}{R}=-2.01+0.63 D_{1} \ln \frac{P_{j}}{P_{i}}+2.17\left(D_{2}+D_{3}\right) \ln \frac{P_{j}}{P_{i}}+3.34 D_{1}-0.13 D \quad \text { adj. } R^{2} \quad 0.966 \quad D W 1.25 \\
& \begin{array}{llll}
(-2.30)(18.12) & (5.44) & (3.82) & (-2.39)
\end{array}
\end{aligned}
$$

$D$ : dummy variables. $D_{l}-D_{3}:$ see Table $5 ; D: 1999,2000=1$, others $=0$.

The figures in parentheses indicate the t-statistics: all are significant at the $1 \%$ level.

Table 4. Correlation between SIRs/R\&D ratio and relative price in Finland (1995-2018).

Source: [9].

Tables 5 and 6 demonstrate that SIRs that substituted for R\&D has spilled over to GTC and removed structural impediments in growth thereby GTC made significant contribution to Finland's GDP growth particularly after the enactment of the Competitiveness Pact in 2016, and enabled Finland's notable resurgence.

Table 5. Governing factors of MFP in Finland (1994-2018).

$$
\begin{aligned}
\ln M F P= & 43.23-0.04 t+0.03 D_{1} \ln R-0.25\left(D_{2}+D_{3}\right) \ln R+1.80 \ln C+0.04 D_{1} \ln I+0.84 D_{2} \ln I+8.96 D_{3} \ln I \\
& (-6.01)(-6.71)(2.75) \quad(-2.56) \\
+ & 38.89 D_{1}+36.87 D_{2}+0.02 D \quad \text { adj. } R^{2} 0.983 D W 2.27 \\
& (6.22) \quad(5.78) \quad(2.91)
\end{aligned}
$$

$D_{i}$ : dummy variables identifying R\&D-driven economic features of respective periods as follows:

\begin{tabular}{llcccl}
\hline & $\begin{array}{c}1994- \\
2009\end{array}$ & $\begin{array}{c}2010- \\
2015\end{array}$ & $\begin{array}{c}2016- \\
2018\end{array}$ & \multicolumn{1}{c}{ Features of the period } \\
\hline$D_{1} \quad 1994-2009=1$, others $=0$ & 1 & 0 & 0 & $\begin{array}{l}\text { Sustainable increase in R\&D intensity that supported } \\
\text { economic growth }\end{array}$ \\
\hline$D_{2}$ & $2010-2015=1$, others $=0$ & 0 & 1 & 0 & \begin{tabular}{l} 
R\&D intensity decline in the economic stagnation \\
\hline$D_{3}$
\end{tabular}$\quad 2016-2018=1$, others $=0$ \\
\hline
\end{tabular}

D: $2000,2001,2007,2010,2011=1$, others $=0$,

The figures in parentheses indicate the t-statistics: all are significant at the $1 \%$ level except $* 110 \%$.

Source: [9].

Table 5 identified that Finland's innovation proxied by multifactor productivity (MFP) was governed by $R \& D(R)$ as a source of technology knowledge stock, spillover SIRs taking the 
Internet dependence similar to Table 4 (I), demand creation (C), and learning effect (t). Table 5 demonstrated that significant contribution to innovation in Finland changed from R\&D to SIRs after 2012, particularly after 2016 corresponding to the enactment of the Competitiveness Pact.

Table 6 demonstrated the similar structure regarding the contribution to GTC (K) increase. SIRs (I) made significant contribution to GTC increase instead of R\&D contribution particularly after 2016.

These analyses support the hypothetical view that SIRs substituted for GSC centered on R\&D and spilled over to GTC leading to removing structural impediments in growth.

$$
\begin{aligned}
& \ln K=-10.87-0.01 t-0.11 D_{1} \ln R+0.59 \ln C+1.15 D_{2} \ln I+2.77 D_{3} \ln I+12.68 D_{1}+7.34 D_{2}-0.01 D \\
& (-2.78)(-3.63)(-4.43) \quad(3.86) \quad(4.90) \quad(3.31) \quad(3.34) \quad(1.94)^{* 1}(-2.65) \\
& \text { adj. } R^{2} 0.922 \quad D W 1.58
\end{aligned}
$$

Backward elimination method with $10 \%$ criteria is used.

The figures in parentheses indicate the t-statistics: significant at the $1 \%$ level except ${ }^{* 1} 10 \%$.

Source: [9].

Table 6. Components of MFP impacting on GTC in Finland (1994-2018).

\subsection{GTC SUBSTITUTION FOR GSC}

Such substitutionary behavior prompts us a hypothetical view that GTC substituted for GSC during the course of resurgence in Finland as illustrated in Fig. 13. This view is supported by the decreasing share in GSC and increasing share of GTC in the gross capital (GC) as demonstrated in Fig. 14.

Inspired by these observation, Fig. 15 analyzed correlation between GSC /GTC prices ratio and GTC/GSC ratio in Finland over the period from 1994-2017. As demonstrated in Table 7 GTC changed to substitution for GSC after 2010.
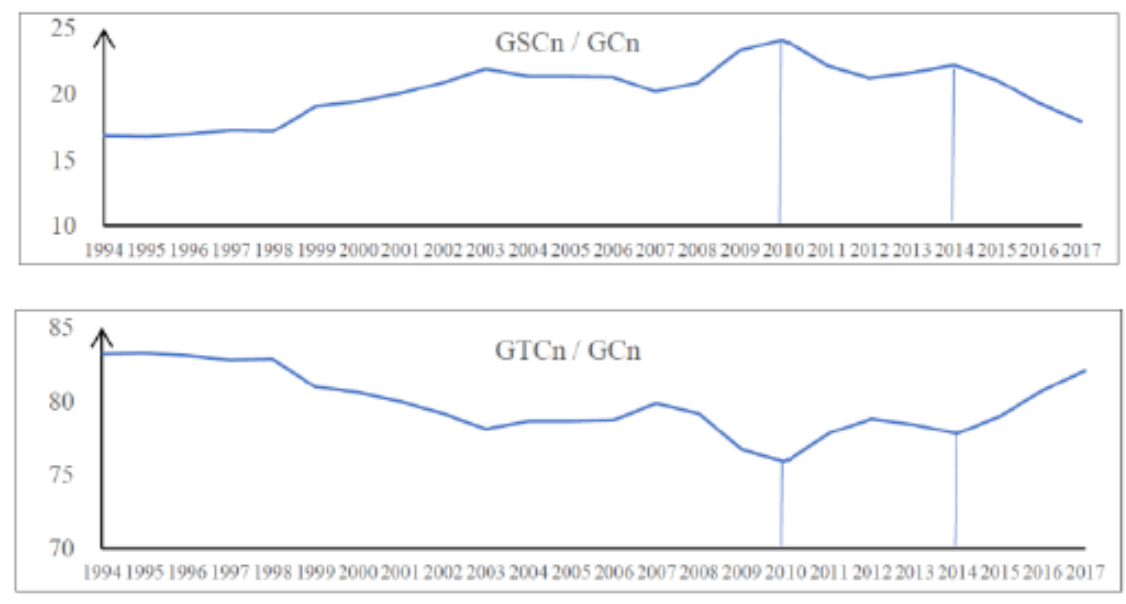

Figure 14. Trends in GSC and GTC shares in Finland (1994-2017) - \%. Source: [30]. 
International Journal of Managing Information Technology (IJMIT) Vol.11, No.2, May 2019

This substitution can be attributed to SIRs that spilled over from GSC to GTC and contributed to removing structural impediments in growth as demonstrated earlier.

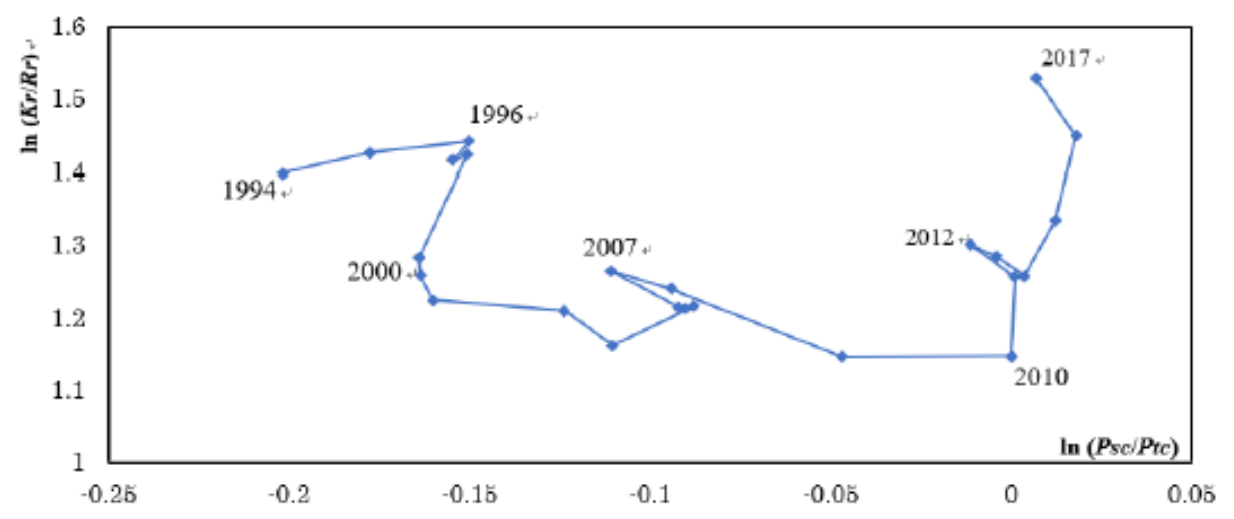

Figure 15. Correlation between GSC/GTC price ratio and GTC/GSC ratio in Finland (1994-2017).

\begin{tabular}{|c|c|c|c|c|c|c|}
\hline$a$ & $\varepsilon_{1}$ & $\varepsilon_{2}$ & $b$ & $c$ & $\operatorname{adj} \cdot R^{2}$ & $D W$ \\
\hline 1.24 & -1.64 & 10.04 & -0.18 & 0.17 & 0.638 & 1.53 \\
\hline$(38.08)$ & $(-4.11)$ & (3.63) & $(-3.00)$ & $(4.05)$ & & \\
\hline
\end{tabular}

D; dimmy variables

$D_{1}: 1994-2009=1$, others $=0 ; D_{2}: 2010-2017=1$, others $=0 ; D: 1996,2012,2017=1$, others $=0$

The figures in parentheses indicate the t-statistics: significant at the $1 \%$ level.

$\ln \frac{K r}{R r}=a+\varepsilon \ln \frac{P S C}{P t c} \quad \varepsilon>1:$ substitution, $1>\varepsilon>0:$ neutral, $\varepsilon<0:$ complement

Table 7. Correlation between GSC/GTC price ratio and GTC/GSC ratio in Finland (1994-2017).

On the basis of these findings, Table 8 summarizes transformation of components of gross capital in the digital economy observed in Finland in its resurging process. It is identified that while GTC substitution for GSC supported by SIRs contributed to resurgence, it is feared that this substitution results in losing timely significant breakthrough opportunity by losing innovation function that is expected to be accumulated in GSC.

Table 8. Transformation of components of gross capital in the digital economy in Finland.

\begin{tabular}{|c|c|c|}
\hline Traditional classification & GSC & GTC \\
\hline Environmental change & $\begin{array}{c}\text { Increasing difficulties, } \\
\text { uncertainties, lengthy pregnant } \\
\text { period, and expenditures }\end{array}$ & $\begin{array}{c}\text { Availability of practical } \\
\text { platform effects, package } \\
\text { software }\end{array}$ \\
\hline Firms/nations behavior & Escape from difficulties & Depending on easy solution \\
\hline National Accounting & Decreasing share after 2010 & $\begin{array}{c}\text { Increasing share after 2010 } \\
\text { (GTC substitutes for GSC) }\end{array}$ \\
\hline Transformation of functions & Losing innovation function & Gaining innovation function \\
\hline Effects & $\begin{array}{c}\text { Losing timely significant } \\
\text { breakthrough opportunity }\end{array}$ & Contribute to resurgence \\
\hline
\end{tabular}


Consequently, IMF has published reserved prospect on Finland's GDP growth toward 2023 as demonstrated in Fig. 16. This forecast sounds the alarm that this transformation may result in canceling the notable resurgence.

Real GDP Growth Rate in 11 Leading Countries (average 2016-2018)

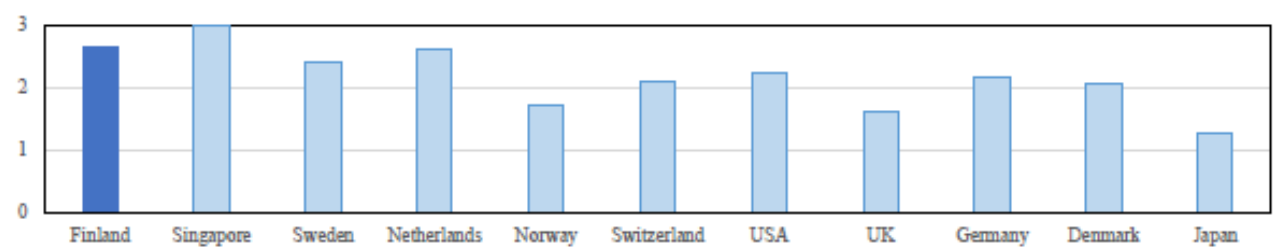

Prospect of Real GDP Growth Rate in 11 Leading Countries (average 2019-2023)

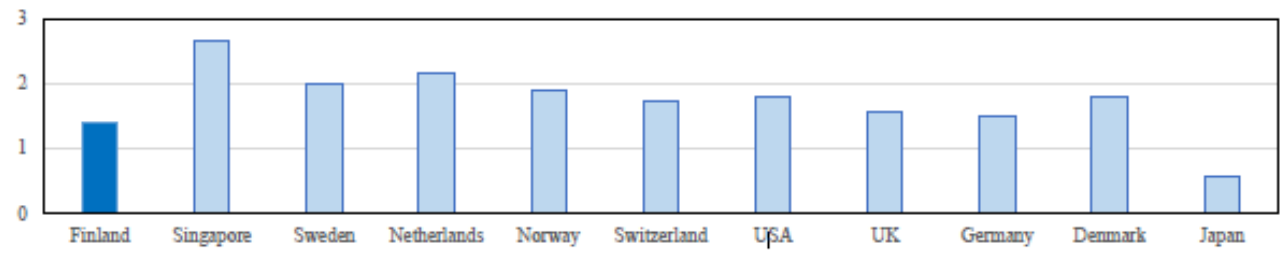

Figure 16. Contrast of notable resurgence and lower growth thereafter in Finland (2016-2023).

Source: [10].

In order to avoid such a pessimistic result, it is strongly required to endeavor comprehensive strategy for the future encompassing (i) prioritize GSC focus that can breakthrough the future path such as AI and digital bioeconomy, (ii) promote priority deployment system, (iii) stimulate GTC development thereby. This development is expected to induce GDP growth that enables GSC increase, and a virtuous cycle can be constructed thereby. This is to construct a complement between GSC and GTC to which Amazon's complementary system between technology and content as demonstrated in Fig. 13 may provide an insightful suggestion.

\subsection{LESSONS FROM AMAZON R\&D MODEL}

Notwithstanding the critical problem of a dilemma between $R \& D$ expansion and productivity decline that a majority of ICT leaders have been confronting in the digital economy, Amazon has been able to accomplish a skyrocketing increase in $R \& D$ and market capitalization as reviewed earlier.

This success can be attributed to its business model that has enabled Amazon to absorb external resources extensively through the Amazon empire chain, big data collection system and architecture for participation, and assimilate them into its business [8].

Given that this model deploys a full-fledged function, it may transform "routine or periodic alterations" (traditionally classified as non-R\&D) into "significant improvement" (classified as $\mathrm{R} \& \mathrm{D})$.

This anticipation leverages Amazon to maintain its fundamental source of its strength, such as having excellent customer service and ensuring complete customer satisfaction through such "species survival and evolution systems" as 
(i) Consistent innovation by means of (a) a peer review system, (b) easy checkouts, (c) usertailored suggested products, (d) making changes proactively, and

(ii) Performing disruption analysis on existing customer data for business changes [31].

A holistic management policy, rather than separate activities contributes to the broad dissemination of this transformation effect. Such transformation exercises are similar to experiments, which Amazon CEO Jeff Bezos has been encouraging [32].

The value created is distributed among various stakeholders: shareholders, employees, executives, customers, creditors, and suppliers.

Under such a distinct CEO's policy and strong leadership thereof, at Amazon, experimentation is always occurring, initiated by employees in broad fields throughout the company, and ideas are constantly being presented to Bezos, leading to the satisfying of the first leadership principle:

\section{Customer obsession.}

Motivated employees understand that these ideas are going to be altered in many ways [33]. Consistent innovative thinking is another resource that Amazon has exploited advantageously [34], [35].

It has been popularized the following mathematical formula that Cash + Willingness to experiment + Stable leadership $=$ Success [36]. It is evident that the company's unique team of employees and Bezos' visionary leadership have been instrumental in Amazon's success [35].

This system enabling Amazon transform "product" focusing on routine or periodic alteration endeavors into "technology" that contributes to significant improvement as illustrated in Fig. 17.

Unlike Apple, Google, and Microsoft, Amazon is not fixated on a tightly designed ecosystem of interlocking apps and services. Bezos instead emphasizes platforms, each of which serves its customers in the best and fastest possible way. That impulse has spawned an awesome stream of creative firsts [37] as if firing from the top right corner of Fig. 17.

Given this impulse, Amazon may explore a newer R\&D model that transforms "content" into "technology" by deploying the full-fledged function of its sophisticated management system to absorb external resources extensively and assimilate them into its business. Noteworthy is that "technology" leverages "product", which in turn induces further advancement of "technology" leading to co-evolutionary complementary system.

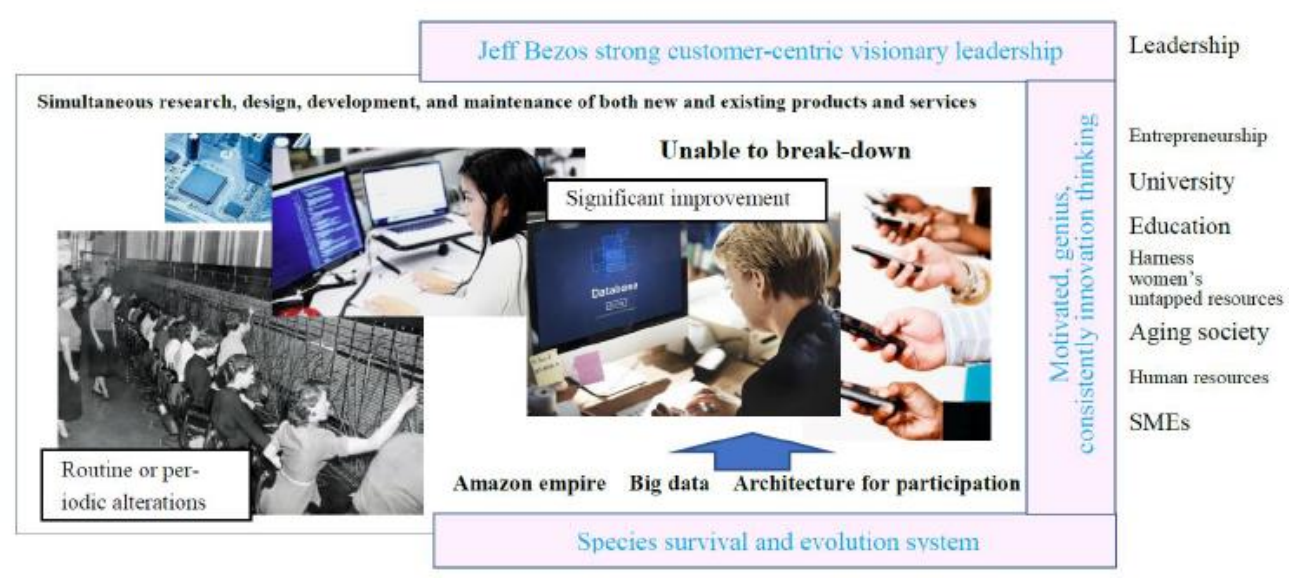

Figure 17. Illustration of Amazon's R\&D. 
This co-evolutionary complementary system between "content" and "technology" provides an insightful suggestion to Finland in constructing complementary system between its GSC and GTC that might nourish timely significant breakthrough opportunity.

\subsection{LEARNING FROM FINLAND NOTABLE RESURGENCE}

Finland's success for its accomplishment of notable resurgence in the digital economy can be highlighted to the following dynamism as illustrated in Fig. 18 [9].

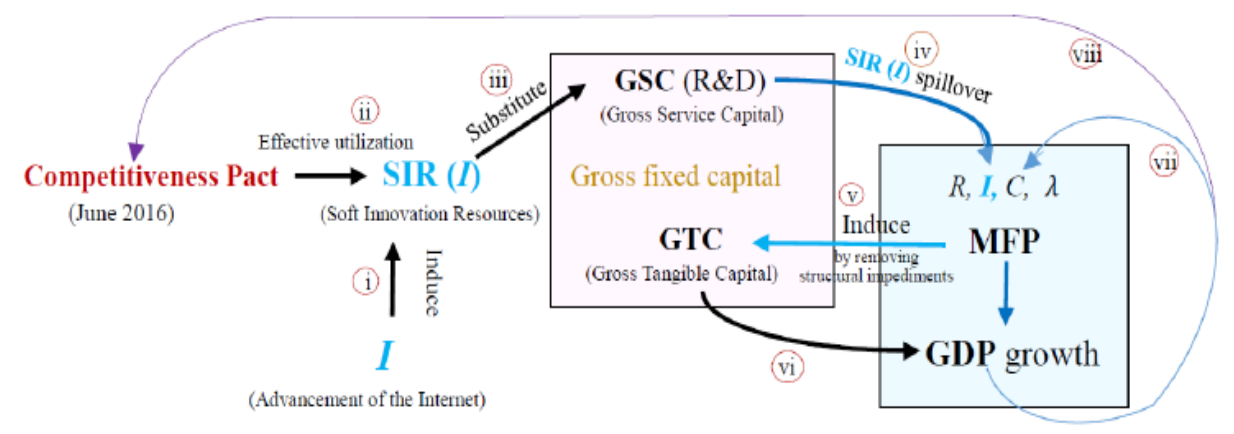

Figure 18. Dynamism of soft innovation resources in removing structural impediments in GTC growth in Finland.

(i) Advancement of the Internet awoke and induced SIRs.

(ii) The Competitiveness Pact spurred effective utilization of SIRs.

(iii) SIRs substituted for GSC (centred on R\&D) supported by uncaptured GDP.

(iv) Through the substitution process SIRs spilled-over and incorporated in GTC via MFP.

(v) MFP induced GTC by removing structural impediments of its increase.

(vi) Increased GTC contributed to GDP growth.

(vii) GDP growth in turn increased MFP leading to a virtuous cycle.

(viii) In addition, GDP resurgence instilled confidence to the Competitiveness Pact.

Finland's success, triggered by the enactment of the Competitiveness Pact in 2016, through exploring elastic labor supply, fostering a trusting relationship between employer and employees, satisfying on demand supply and trans generational preferences towards an aging society [9] may provide Amazon an insightful suggestion for solving its critical problems with respect to consensus gaining among stakeholders, instilling confidence in employees, and also to corresponding to new monopoly issues [16].

\section{Conclusion}

In light of the critical problem of a dilemma between R\&D expansion and productivity decline that a majority of ICT leaders have been confronting in the digital economy, this paper attempted to find a constructive solution to this critical problem.

Inspired by notable successes initiated by two ICT leaders, Amazon and Finland, the sources of their success were identified by means of a comparative empirical analysis of their development trajectories.

ICT-driven development trajectory incorporates a bipolarization fatality which emerges uncaptured GDP and urges highly R\&D intensive economies confront the dilemma between R\&D expansion and productivity decline. 
Solution to this dilemma is to activate latent self-propagating function indigenous to ICT through gross R\&D increase by harnessing the vigor of external innovation resources, particularly of soft innovation resources (SIRs) in the marketplace.

Amazon has established a sophisticated R\&D model enabling it to absorb such resources extensively through the Amazon empire chain, big data collection system and architecture for participation with sophisticated management system that maximizes a full-fledged function, and assimilate them into its business. It transformed "content" focusing on routine or periodic alteration endeavors into "technology" that contributes to significant improvement.

Contrary to such Amazon's complementary use of SIRs, Finland has depended on substitutional use. SIRs substituted for R\&D and spilled over to the gross tangible capital, and then removed structural impediments to growth.

While this approach contributed to easy resurgence, it may lose timely significant breakthrough opportunity expected to be initiated by innovative $R \& D$ endeavor. This lost is feared to cancel the success in resurgence in the future.

In order to avoid such a fear, it is strongly required to endeavor comprehensive strategy for the future encompassing (i) prioritize GSC focus that can breakthrough the future path such as AI and digital bioeconomy, (ii) promote priority deployment system, (iii) stimulate GTC development thereby. This development is expected to induce GDP growth which enables GSC increase, and a virtuous cycle can be constructed thereby.

This is to construct a complement between GSC and GTC to which Amazon's complementary system between technology and content may provide an insightful suggestion.

At the same time, Finland's success, triggered by the enactment of the Competitiveness Pact in 2016, through exploring elastic labor supply, fostering a trusting relationship between employer and employees, satisfying on demand supply and transgenerational preferences towards an aging society may provide Amazon an insightful suggestion for solving its critical problems with respect to consensus gaining among stakeholders, instilling confidence in employees, and also to corresponding to new monopoly issues.

Future work should focus on accrual of these cross learning to general policy ecosystems.

\section{ACKNOWLEDGEMENTS}

The research leading to these results is the part of a project: Platform Value Now: Value capturing in the fast emerging platform ecosystems, supported by the Strategic Research Council at the Academy of Finland [grant number 293446]. 
International Journal of Managing Information Technology (IJMIT) Vol.11, No.2, May 2019

\section{APPENDIX BASIC STATISTICS FOR THE ANALYSIS}

Table A1 Trends in Real GDP Growth Rate and Happiness Score

\begin{tabular}{|c|c|c|c|c|c|c|c|c|c|c|c|}
\hline & Finland & Singapore & Sweden & $\begin{array}{l}\text { Nether } \\
\text { lands }\end{array}$ & Norway & $\begin{array}{l}\text { Switzer } \\
\text { land }\end{array}$ & USA & UK & Germany & Denmark & Japan \\
\hline 1990 & 0.68 & 10.04 & 0.80 & 4.18 & 1.93 & 3.57 & 1.89 & 0.74 & 5.72 & 1.47 & 4.89 \\
\hline 1991 & -5.92 & 6.69 & -1.03 & 2.45 & 3.09 & -0.82 & -0.11 & -1.09 & 5.01 & 1.4 & 3.42 \\
\hline 1992 & -3.33 & 7.09 & -0.98 & 1.59 & 3.57 & -0.17 & 3.52 & 0.37 & 1.51 & 1.96 & 0.85 \\
\hline 1993 & -0.73 & 11.54 & -1.85 & 1.26 & 2.85 & -0.12 & 2.75 & 2.53 & -0.99 & 0.01 & -0.52 \\
\hline 1994 & 3.94 & 10.93 & 4.09 & 3.01 & 5.06 & 1.32 & 4.03 & 3.90 & 2.53 & 5.33 & 0.99 \\
\hline 1995 & 4.21 & 7.03 & 4.02 & 2.76 & 4.15 & 0.54 & 2.68 & 2.46 & 1.81 & 3.03 & 2.74 \\
\hline 1996 & 3.66 & 7.53 & 1.52 & 3.49 & 5.03 & 0.53 & 3.77 & 2.54 & 0.86 & 2.91 & 3.10 \\
\hline 1997 & 6.25 & 8.29 & 2.91 & 4.33 & 5.29 & 2.33 & 4.45 & 4.29 & 1.91 & 3.26 & 1.08 \\
\hline 1998 & 5.43 & -2.23 & 4.24 & 4.67 & 2.62 & 2.93 & 4.48 & 3.34 & 1.77 & 2.21 & -1.13 \\
\hline 1999 & 4.44 & 6.10 & 4.49 & 5.03 & 2.01 & 1.65 & 4.75 & 3.21 & 1.84 & 2.95 & -0.25 \\
\hline 2000 & 5.64 & 8.90 & 4.75 & 4.2 & 3.21 & 4.08 & 4.13 & 3.45 & 3.19 & 3.75 & 2.78 \\
\hline 2001 & 2.58 & -0.95 & 1.57 & 2.33 & 2.09 & 1.28 & 1.00 & 2.84 & 1.83 & 0.82 & $\overline{0.41}$ \\
\hline 2002 & 1.68 & 4.21 & 2.08 & 0.22 & 1.44 & 0.19 & 1.74 & 2.50 & 0.03 & 0.47 & $\overline{0.12}$ \\
\hline 2003 & 1.99 & 4.44 & 2.36 & 0.16 & 0.92 & 0.07 & 2.86 & 3.34 & -0.72 & 0.39 & 1.53 \\
\hline 2004 & 3.93 & 9.55 & 4.31 & 1.98 & 3.96 & 2.62 & 3.80 & 2.35 & 0.70 & 2.67 & 2.21 \\
\hline 2005 & 2.78 & 7.49 & 2.82 & 2.05 & 2.63 & 3.16 & 3.51 & 3.15 & 0.87 & 2.34 & 1.66 \\
\hline 2006 & 4.06 & 8.86 & 4.70 & 3.46 & 2.40 & 4.08 & 2.86 & 2.55 & 3.89 & 3.91 & $\overline{1.42}$ \\
\hline 2007 & 5.19 & 9.11 & 3.41 & 3.77 & 2.99 & 4.11 & 1.88 & 2.55 & 3.37 & 0.91 & 1.65 \\
\hline 2008 & 0.72 & 1.79 & -0.56 & 2.17 & 0.48 & 2.11 & -0.14 & -0.35 & 0.81 & -0.51 & -1.09 \\
\hline 2009 & -8.27 & -0.60 & -5.20 & -3.67 & -1.69 & -2.23 & -2.54 & -4.25 & -5.56 & -4.91 & -5.42 \\
\hline 2010 & 2.99 & 15.24 & 5.99 & 1.34 & 0.69 & 2.87 & 2.56 & 1.71 & 3.94 & 1.87 & $\overline{4.19}$ \\
\hline 2011 & 2.57 & 6.35 & 2.68 & 1.55 & 0.97 & 1.84 & 1.55 & 1.65 & 3.72 & 1.34 & -0.12 \\
\hline 2012 & -1.43 & 4.08 & -0.30 & -1.03 & 2.72 & 1.01 & 2.25 & 1.45 & 0.69 & 0.23 & 1.50 \\
\hline 2013 & -0.76 & 5.11 & 1.24 & -0.13 & 1.04 & 1.88 & 1.84 & 2.05 & 0.61 & 0.94 & 2.00 \\
\hline 2014 & -0.63 & 3.88 & 2.60 & 1.42 & 1.98 & 2.49 & 2.45 & 2.95 & 2.18 & 1.62 & 0.38 \\
\hline 2015 & 0.14 & 2.24 & 4.46 & 1.96 & 1.97 & 1.27 & 2.88 & 2.35 & 1.48 & 1.61 & 1.35 \\
\hline 2016 & 2.48 & $2.40^{\circ}$ & 2.68 & 2.19 & 1.09 & 1.59 & 1.57 & 1.79 & 2.16 & 1.97 & $\overline{0.96}$ \\
\hline 2017 & 2.80 & 3.62 & 2.11 & 2.87 & 1.92 & 1.67 & 2.22 & 1.66 & 2.46 & 2.28 & 1.74 \\
\hline 2018 & 2.65 & 2.93 & 2.42 & 2.81 & 2.11 & 3.01 & 2.88 & 1.36 & 1.91 & 1.96 & 1.14 \\
\hline 2019 & 1.80 & 2.50 & 2.20 & 2.60 & 2.10 & 1.80 & 2.50 & 1.50 & 1.90 & 1.90 & 0.90 \\
\hline 2020 & 1.60 & 2.70 & 2.00 & 2.30 & 1.90 & 1.70 & 1.80 & 1.50 & 1.60 & 1.80 & 0.30 \\
\hline 2021 & 1.20 & 2.70 & 2.00 & 2.10 & 1.90 & 1.70 & 1.70 & 1.60 & 1.50 & 1.80 & 0.70 \\
\hline 2022 & 1.20 & 2.70 & 1.90 & 2.00 & 1.80 & 1.70 & 1.50 & 1.60 & $1.30^{\circ}$ & $1.70^{\circ}$ & 0.50 \\
\hline 2023 & 1.20 & 2.60 & 1.90 & 1.80 & 1.80 & 1.70 & 1.40 & 1.60 & 1.20 & 1.70 & 0.50 \\
\hline $\begin{array}{l}\text { Average } \\
2010-12 \\
\end{array}$ & 1.38 & 8.56 & 2.79 & 0.62 & 1.46 & 1.91 & 2.12 & 1.60 & 2.78 & 1.15 & 1.86 \\
\hline $\begin{array}{l}\text { Average } \\
2013-15\end{array}$ & -0.42 & 3.74 & 2.77 & 1.08 & 1.66 & 1.88 & 2.39 & 2.45 & 1.42 & 1.39 & 1.24 \\
\hline $\begin{array}{l}\text { Average } \\
2016-18\end{array}$ & 2.64 & 2.98 & 2.40 & 2.62 & 1.71 & 2.09 & 2.22 & 1.60 & 2.18 & 2.07 & 1.28 \\
\hline $\begin{array}{l}\text { Average } \\
2019-23\end{array}$ & 1.40 & 2.64 & 2.00 & 2.16 & 1.90 & 1.72 & 1.78 & 1.56 & 1.50 & 1.78 & 0.58 \\
\hline $\begin{array}{l}\text { Happiness } \\
\text { score } \\
\text { (Ranking } \\
\text { out of } 156 \text { ) }\end{array}$ & $\begin{array}{l}7.63 \\
(1)\end{array}$ & $\begin{array}{l}6.34 \\
(34)\end{array}$ & $\begin{array}{l}7.31 \\
(9)\end{array}$ & $\begin{array}{l}7.44 \\
(6)\end{array}$ & $\begin{array}{c}7.59 \\
(2)\end{array}$ & $\begin{array}{l}7.49 \\
(5)\end{array}$ & $\begin{array}{l}6.89 \\
(18)\end{array}$ & $\begin{array}{l}6.81 \\
(19)\end{array}$ & $\begin{array}{l}6.96 \\
(15)\end{array}$ & $\begin{array}{l}7.56 \\
(3)\end{array}$ & $\begin{array}{l}5.91 \\
(54)\end{array}$ \\
\hline
\end{tabular}

Sources: [10], [11]. 
International Journal of Managing Information Technology (IJMIT) Vol.11, No.2, May 2019

Table A2 Trends in Gross Capital and Its Components in Finland (1994-2017)

\begin{tabular}{ccccccccccc}
\hline & GCn & GCr & GSCn & Rr & GTCn & Kr & Psc & Ptc & $\begin{array}{c}\text { GSCn } / \\
\text { GCn }\end{array}$ & $\begin{array}{c}\text { GTCn/ } \\
\text { GCn }\end{array}$ \\
\hline $\mathbf{1 9 9 4}$ & 16924 & 22394 & 2844 & 4438 & 14080 & 17956 & 0.64 & 0.78 & 16.8 & 83.2 \\
\hline $\mathbf{1 9 9 5}$ & 18996 & 25202 & 3183 & 4884 & 15813 & 20318 & 0.65 & 0.78 & 16.8 & 83.2 \\
\hline $\mathbf{1 9 9 6}$ & 20928 & 27726 & 3542 & 5307 & 17386 & 22419 & 0.67 & 0.78 & 16.9 & 83.1 \\
\hline $\mathbf{1 9 9 7}$ & 23668 & 30743 & 4078 & 6010 & 19590 & 24733 & 0.68 & 0.79 & 17.2 & 82.8 \\
\hline $\mathbf{1 9 9 8}$ & 26755 & 34025 & 4595 & 6609 & 22160 & 27416 & 0.70 & 0.81 & 17.2 & 82.8 \\
\hline $\mathbf{1 9 9 9}$ & 28482 & 35565 & 5428 & 7723 & 23054 & 27842 & 0.70 & 0.83 & 19.1 & 80.9 \\
\hline $\mathbf{2 0 0 0}$ & 31457 & 37776 & 6114 & 8359 & 25343 & 29417 & 0.73 & 0.86 & 19.4 & 80.6 \\
\hline $\mathbf{2 0 0 1}$ & 33080 & 38440 & 6627 & 8735 & 26453 & 29705 & 0.76 & 0.89 & 20.0 & 80.0 \\
\hline $\mathbf{2 0 0 2}$ & 32071 & 37304 & 6691 & 8572 & 25380 & 28732 & 0.78 & 0.88 & 20.9 & 79.1 \\
\hline $\mathbf{2 0 0 3}$ & 33052 & 38348 & 7236 & 9142 & 25816 & 29206 & 0.79 & 0.88 & 21.9 & 78.1 \\
\hline $\mathbf{2 0 0 4}$ & 35333 & 40136 & 7543 & 9176 & 27790 & 30960 & 0.82 & 0.90 & 21.3 & 78.7 \\
\hline $\mathbf{2 0 0 5}$ & 37739 & 41440 & 8059 & 9495 & 29680 & 31945 & 0.85 & 0.93 & 21.4 & 78.6 \\
\hline $\mathbf{2 0 0 6}$ & 39334 & 41983 & 8375 & 9605 & 30959 & 32378 & 0.87 & 0.96 & 21.3 & 78.7 \\
\hline $\mathbf{2 0 0 7}$ & 45103 & 46171 & 9094 & 10162 & 36009 & 36009 & 0.89 & 1.00 & 20.2 & 79.8 \\
\hline \hline $\mathbf{2 0 0 8}$ & 47245 & 46298 & 9848 & 10390 & 37397 & 35908 & 0.95 & 1.04 & 20.8 & 79.2 \\
\hline $\mathbf{2 0 0 9}$ & 41187 & 40489 & 9589 & 9768 & 31598 & 30721 & 0.98 & 1.03 & 23.3 & 76.7 \\
\hline $\mathbf{2 0 1 0}$ & 40933 & 40933 & 9867 & 9867 & 31066 & 31066 & 1.00 & 1.00 & 24.1 & 75.9 \\
\hline $\mathbf{2 0 1 1}$ & 43779 & 42610 & 9711 & 9444 & 34068 & 33166 & 1.03 & 1.03 & 22.2 & 77.8 \\
\hline $\mathbf{2 0 1 2}$ & 44610 & 41782 & 9464 & 8943 & 35146 & 32839 & 1.06 & 1.07 & 21.2 & 78.8 \\
\hline $\mathbf{2 0 1 3}$ & 43083 & 39718 & 9310 & 8610 & 33773 & 31108 & 1.08 & 1.09 & 21.6 & 78.4 \\
\hline $\mathbf{2 0 1 4}$ & 42235 & 38694 & 9376 & 8566 & 32859 & 30128 & 1.09 & 1.09 & 22.2 & 77.8 \\
\hline $\mathbf{2 0 1 5}$ & 42713 & 38976 & 8991 & 8126 & 33722 & 30850 & 1.11 & 1.09 & 21.0 & 79.0 \\
\hline $\mathbf{2 0 1 6}$ & 46844 & 42321 & 9044 & 8053 & 37800 & 34268 & 1.12 & 1.10 & 19.3 & 80.7 \\
\hline $\mathbf{2 0 1 7}$ & 49591 & 44145 & 8886 & 7866 & 40705 & 36279 & 1.13 & 1.12 & 17.9 & 82.1 \\
\hline & & & & & & & & & & \\
\hline
\end{tabular}

Source: [30].

\section{REFERENCES}

[1] Tou, Y., Watanabe, C., Moriya, K., \& Neittaanmäki, P., 2018b. Neo Open Innovation in the Digital Economy: Harnessing Soft Innovation Resources. International Journal of Managing Information Technology 10 (4), 53-75.

[2] Tou, Y., Watanabe, C., Moriya, K., \& Neittaanmäki, P., 2019b. Harnessing Soft Innovation Resources Leads to Neo Open Innovation. Technology in Society, in print.

[3] B loomberg, 2017. 2017 Global Innovation 1000 Study. Blo omberg, New York. 
International Journal of Managing Information Technology (IJMIT) Vol.11, No.2, May 2019

[4] Fox, J., 2018. Amazon, the Biggest R\&D Spender, Does Not Believe in R\&D. Bloomberg Opinion, 13 April 2018.

https://www.bloomberg.com/view/articles/2018-04-12/amazon-doesn-t-believe-in-research-anddevelopment-spending (retrieved 22.09.2018).

[5] Statista, 2019. Top Internet Companies: Global Market Value 2018. Statista, Hamburg. https://www.statista.com/statistics/277483/market-value-of-the-largest-internet-companiesworldwide/ (retrieved 10.01.2019).

[6] Macrotrends, 2019. Apple Market Cap 2006-2018 - AAPL, Chicago. https://www.macrotrends.net/stocks/charts/AAPL/apple/market-cap (retrieved 08.02.2019).

[7] Macrotrends, 2019. Amazon Market Cap 2006-2018 - AMZN, Chicago. https://www.macrotrends.net/stocks/charts/AMZN/amazon/market-cap (retrieved 08.02.2019).

[8] Tou, Y., Watanabe, C., Moriya, K., Vurpillat, V., \& Neittaanmäki, P., 2019a. A New Concept of R\&D in Neo Open Innovation: Transformation of R\&D Triggered by Amazon. International Journal of Managing Information Technology 11 (1) in print.

[9] Tou, Y., Watanabe, C., Ilmola, L., Moriya, K. and Neittaanmäki, P., 2018a. Hybrid Role of Soft Innovation Resources: Finland's Notable Resurgence in the Digital Economy. International Journal of Managing Information Technology 10 (4), 1-22.

[10] International Monetary Fund (IMF), 2018. World Economic Outlook Database 2018. IMF, Washington, D.C.

https://www.imf.org/external/datamapper/NGDP_RPCH@WEO/OEMDC/ADVEC/WEOWORLD (retrieved 06.02.2019).

[11] United Nations, 2018. World Happiness Report 2018. United Nations, New York. http://worldhappiness.report/ed/2018/ (retrieved 10.01.2019)

[12] Kenney, M., 2013. The Growth and Development of the Internet in the United States. In: Cogut B, Ed. The Global Internet Economy. MIT Press, Massachusetts.

[13] R i tala, P., Golnam, A. \& Wegmann, A., 2014. Coopetition based Business Models: The Case of Amazon.com. Industrial Marketing Management 43, 236249.

[14] K nott, A.M., 2017. How Innovation Really Works: Using the Trillion Dollar R\&D fix to Drive Growth. McGraw Hill , New

[15] Galloway, S., 2017. The Hidden DNA of Amazon, Apple, Facebook, and Google. Penguin Random House LLC, New York.

[16] Khan, L.L., 2017. Amazon's Antitrust Pradox. The Yale Law Journal 126, 710-805.

[17] OECD, 2017. OECD Review of Innovation Policy: Finland Assessment and Recommendation. OECD, Paris.

[18] Watanabe, C., Kondo, R., Ouchi, N., Wei, H. and Griffy-Brown, C., 2004. Institutional Elasticity as a Significant Driver of IT Functionality Development. Technological Forecasting and Social Change 71 (7), 723-750.

[19] Schelling, T.C., 1998. Social mechanisms and social dynamics, in Hedstrom, P. and Swedberg, R. eds., Social Mechanisms: An Analytical Approach to Social Theory. Cambridge Univ. Press, Cambridge, 32-43.

[20] International Monetary Fund (IMF), 2017. World Economic Outlook Database 2017. IMF, Washington, D.C.

[21] World Economic Forum (WEF), 2016. The Global Information Technology Report 2016. WEF, Geneva.

[22] EU, 2017. Economics of Industrial Research and Innovation, EU, Brussels.

[23] Watanabe, C., Tou, Y. and Neittaanmäki, P., 2018a. A New Paradox of the Digital Economy: Structural Sources of the Limitation of GDP Statistics. Technology in Society 55, 9-23.

[24] Watanabe, C., Naveed, K., Tou, Y. and Neittaanmäki, P., 2018b. Measuring GDP in the Digital Economy: Increasing Dependence on Uncaptured GDP. Technological Forecasting and Social Change 137, 226-240.

[25] Watanabe, C., Lei, S. and Ouchi, N., 2009. Fusing Indigenous Technology Development and Market Learning for Greater Functionality Development: An Empirical Analysis of the Growth Trajectory of Canon Printers. Technovation 29 (2), 265-283.

[26] Watanabe, C., Takayama, M., Nagamatsu, A., Tagami, T. and Griffy-Brown, C., 2002. Technology Spillover as a Complement for High Level R\&D Intensity in the Pharmaceutical Industry. Technovation 22 (4), 245-258.

[27] Watanabe, C., Naveed, K. and Zhao, W., 2015a. New Paradigm of ICT Productivity: Increasing Role of Un-captured GDP and Growing Anger of Consumers. Technology in Society 41, 21-44. 
International Journal of Managing Information Technology (IJMIT) Vol.11, No.2, May 2019

[28] Watanabe, C., Naveed, K. and Neittaanmäki, P., 2015b. Dependency on Un-captured GDP as a Source of Resilience beyond Economic Value in Countries with Advanced ICT Infrastructure: Similarities and Disparities between Finland and Singapore. Technology in Society 42, 104-122.

[29] Watanabe, C., Naveed, K., Neittaanmäki, P. and Tou, Y., 2016. Operationalization of Un-captured GDP: The Innovation Stream under New Global Mega-trends. Technology in Society 45, 58-77.

[30] Statistics Finland, (2018) "National Accounts of Finland," Statistics Finland, Helsinki.

[31] University of Toronto, 2013. Amazon Business Model Case Study. APS1012 Management of Innovation - Final Team Projects, Spring 2013. University of Toronto, Faculty of Applied Science and Engineering, Toronto.

http://www.amgimanagement.com/founder/ProjectSummaries/APS1012_2013_spring_03_Amazon\% 20business\%20model\%20case\%20study.pdf (retrieved 10.01.2019).

[32] Bezos, J.P., 2013. 2013 Letter to Shareholders. Amazon.com, Inc., Seattle.

[33] Rivet, D.J., 2017. Amazon's Superior Innovation: A Study of Amazon's Corporate Structure, CEO, and Reasons behind Why It has become the Most Innovative Company in Today's Market. University of New Hampshire Honors Theses and Capstone 343, University of New Hampshire, Durham. https://scholars.unh.edu/honors/343 (retrieved 10.01.2019).

[34] Malczewski, B., 2011. Amazon in Overdrive: Is there More to the Overdrive - Amazon Deal than Just the Kindle? Journal of Electronic Resources Librarianship, 23 (4), 404-408.

[35] Izogo, E.E. \& Ozo, J.U., 2015. Critical Evaluation of How Well Placed Amazon is to Sustain its Historical Online Retailing. British Journal of Marketing Studies 3 (6), 31-42.

[36] Levinson,M., 2007. Amazon's IT Leader Leaving Huge Customer Service Infrastructure as Legacy. CIO, 17 Oct. 2007.

https://www.cio.com/article/2437865/infrastructure/amazon-com-s-it-leader-leaving-huge-customerservice-infrastructure-as-legacy.html (retrieved 10.01.2019).

[37] Robischon, N., 2017. Why Amazon is the World's Most Innovative Company of 2017? Fast Company Magazine, 2 May 2017. https://www.fastcompany.com/3067455/why-amazon-is-the-worlds-most-innovative-company-of2017 (retrieved 10.01.2019).

\section{AUTHORS}

Yuji Tou graduated from Tokyo Institute of Technology, Japan, and is currently specially appointed associate professor at Tokyo Institute of Technology, Japan (tou.yuji@gmail.com).

Chihiro Watanabe graduated from the University of Tokyo, Japan, and is currently Professor Emeritus at the Tokyo Institute of Technology, a research professor at the University of Jyväskylä, Finland, and a research scholar at the International Institute for Applied Systems Analysis (IIASA). (watanabe.c.pqr@gmail.com).

Kuniko Moriya graduated from Aoyama Gakuin University, Japan, and is currently is currently Director of the Bank of Japan. (kuniko.moriya@boj.or.jp).

Pekka Neittaanmäki graduated from the University of Jyväskylä with a degree in Mathematics. He is currently Professor of the Faculty of Information Technology, University of Jyväskylä, Finland. (pekka.neittaanmaki@jyu.fi). 